
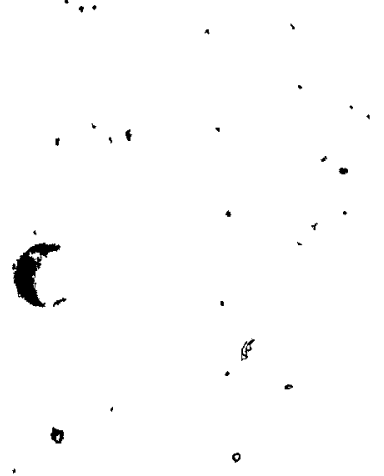

A DIACHRONIC "TREATMENT OF - ENGLISH QUANTIFIERS." by

ANITA MARIE CARLSON

B.A. 'University of Michigan

(1971)

SUBMITTED IN PARTIAL FUULFTLLMENT

OF THE REQUIREMENTS FOR THE DEGREE OF MASTER OF ARTS

at

McGill University

Montreal

August 1976

$K^{*}$ 


\section{A DIACHRONIC TREATMENT OF ENGLISH, QUANTIFIERS}

$$
\text { by }
$$

Anita Marie Carlson

Submitted to the Department of Iinguistics in partial fulfillment of the requirements for' the degree of Master of Apts.

\section{ABSTRACT}

This study presents an analysis of the history of English quantiflers (each, all, both, some, lny, etc.) in which 1t is proposed that these words are best analyzed as members of the syntactic category of adjectives until the end of the sixteenth century when they were re-analyzed as a separate category. Historical changes involving each in the each(...)other reolprocal construct ton are described; the explanation of these changes $1 \mathrm{~s}^{\circ}$ constdered in terms of its ability to provide evidence in the decision between two competing synchronic analyses of the each(...)other construction in Mónern English. Both re-analyses are seen as examples of the types of contribution that diachronic studies can make to the synchronic study of language.

Thesis Supervisor: David Lightfoot Title: Asseciate Professor of Linguistics 
UN ANALYSE D'HISTOIRE D'ANGLETERRE'

À DÉTERMINER LES QUUANTTTÉS

\author{
Anita Marie Carision
}

ABRÉGE'

: Cet étude présent un analyse d'histołre d'Angleterre à déterminer les quantités (each, all, both, some, any,....) de lesquelles 11 est proposé que ces mots sont mieux analysé comme membre de cat'égorie syntaxique d'ajectís jusqu'avant le seizieme siecile quand 11 s ont été reanalysé, commè une catégorie à part. Changement historique Impliquant each dáns each(...)other construction réciproque sont décrit; 1 'explication de ces changèments est considéré en terms d'hablieté pour fournir de l'évidence dans la déciston entre deux analyse synchronique concurrent de each(. . . ) other construction dans 'i'angla1s modern. Les deux re-analyse, sont observé comme examples des genre de contribution que iles études historlque peuvent faire à l'étude synchronlque de langage.

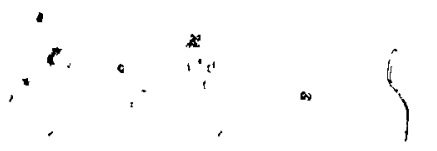

Présentée au Département de Linguistique comme partie des "épreuvels requises pour l'acquisition du grade. de. 'Master. of Arts.

Directeur de thèse: DaviduLightroöt

Titre: Professeur associéde Linguistique 


\section{ACKNOWLEDAEMENTS}

David Lightfoot, deserves special thanks for his many helpful comments and-suggestions; this thesis has benefitted greatiy from'his interest and encouragement.

: I. am grateful to Michael Canale for helplng in the tránslation of old English and Middle Englishrluotations:

:I thank Neil Hunter for proof-reading the manuscript.
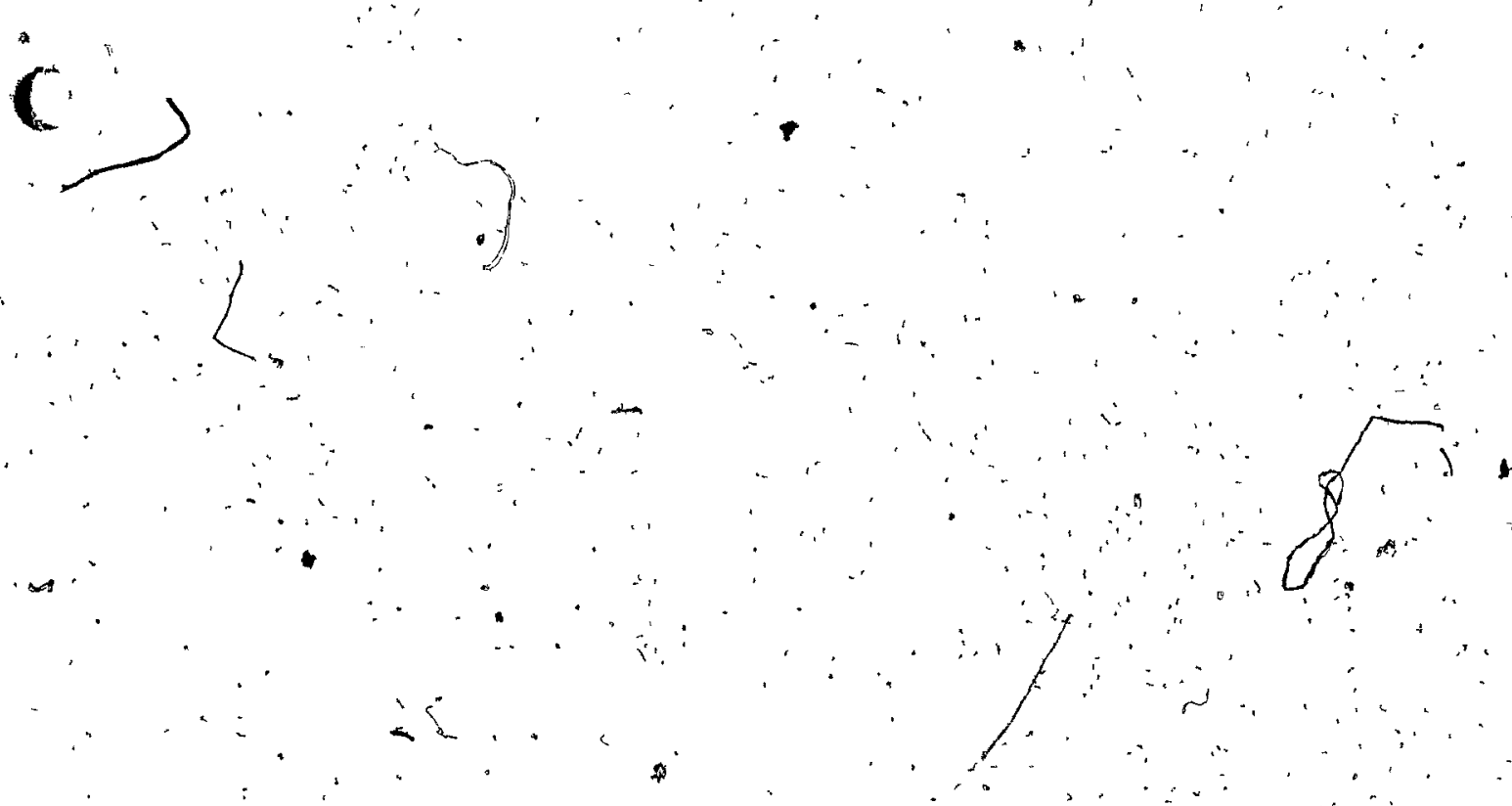
PABLE OF CONTENTS

CHAPTER 1: INTRODUCTION

CHAPTER 2: THE HISTORY QF QUANTIFEERS.

\section{Old. English:}

Inflection of adjectives and quantiflers in $\mathrm{OE} . \ldots 18$

The type 'ali boys'

.21

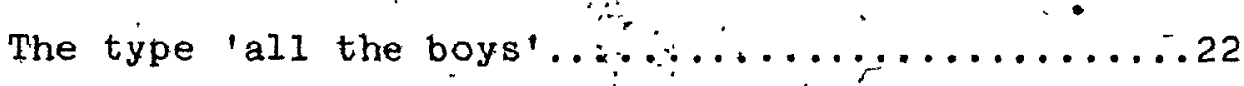

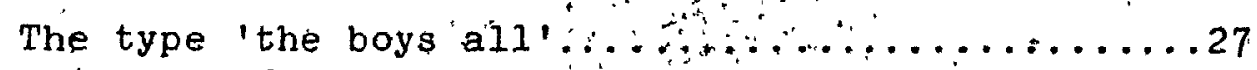

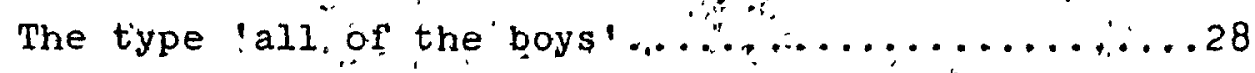

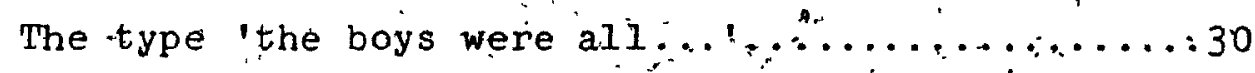

Adjectives and quantiflès used substantivaliy ....32.

Middle Engilsh and Later

Inflection of adjectives and quaritifiers. $\ldots \ldots \ldots 34$

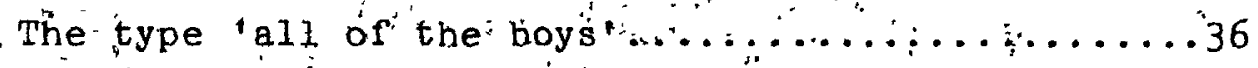

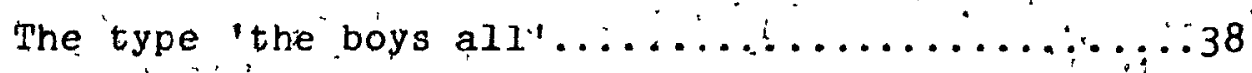

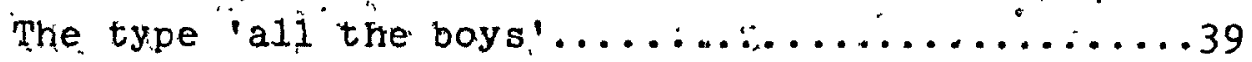

The type the boys were ail ... . . . . . . . . . . 41

s. Adjectives and quantiflers used substantivally . . . 44

Quantifiers as a class ..................48

Evidence of confusion before the re-analysis.....49

Changes caused by the re-analysis .................

Concluston.........................

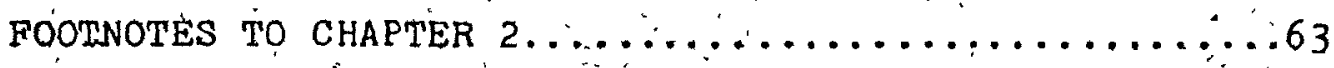


CHAPTER $3:^{\circ}$ 'THE', EACH OTHER' RECIPROCAL CONSTRUCTION' 67 ,

- Types of reclprocal constructions.

Each and other as adjectives in $O E$ and MB;...

The case system and each other ..............80

Each otheris..........................

The types 'each to other' and 'to each other' $\therefore . .889$

The explanation of the historical changes

in the 'each other' construction.............9.

The each-Interpretation analysis of the

diachronlic changes in the, 'each other'

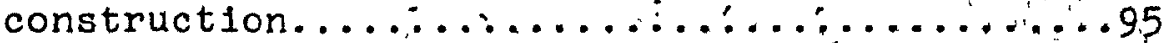

The each-Movement analysis of the diachronic

changes in the 'each other' construction......:1,07

Conclusion., .............................

- FOOTNOTES TO CHAPTER $3 \ldots \ldots \ldots, \ldots \ldots \ldots \ldots \ldots \ldots \ldots \ldots \ldots$

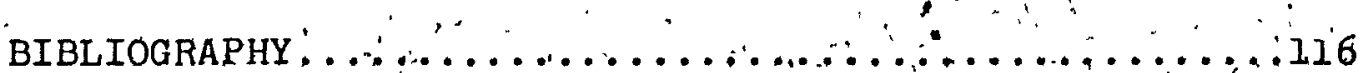

( 
CHAPTER I.

\section{INT́RODUCTIÓN}

Historical change in language has been a topic of Interest for a long time. The purposes of study 1 ing diachronic change have varied from tracing thé parentáge of languages and constructing trees of language samilies to at tempting to determine- how and when a given change in à language took place. The purpose of the present study is closer to that' of the latter type, but it does not stop with the hlstory. of a language; 1t is based on an approach to linguistics that proposes that the results of diachronic studies can contribute to the synchronic study of language. A fulier, description of the approach to be taken here is to be found In Lightroot (1976), on which this brief account is based.

- With the development of transformational-generative grammar lingulsts have a way of viewing and describing syntactic change in language that was not provided by the neogrammarian approach. As Lightfoot (1976). points out; the neogrammarian approach was noticeably inadequate for studies. of diachronic syntax. It allowed a means of expressing phonological changes by the writing of rules to.correlate a given element of the phonological inventory at one time with an element/elements at another time, but a corresponding attempt to relate a sentence at one time with a sentence -at another time is senseless. 
Transformational-generative grammar allows the Iinguist to view (superficlal) changes in a language as changes in the abstract, formal system of rules that generates the language. One change in the abstract system (1.e., the grammar) may result in several. changes in the language output; to study diachrontc change a linguist reverses the direction and, observing several changes occurring at the same time in a given language, looks for one change in the grammar of the language that would explain his observations. He proposes one' gramír for the lianguage at the earlier perlod and another for the later period; basing his proposed grammars on 'the' language data of. each period as well as on the necessity of explaining the differences in the language data observed at the two different times." With this ap'proach the study of diachronic, syntax.is' possible.

Although it is concelvable that a language could undergo several unrelated changes at one time, the number of changes that can occur simultaneously is quite limited since mutual-1ntelligibility must be preserved between the speakers of the language before the change(s) and those after the change(s) Therefore it is Justifiable to say that in the s.tudy of diachronic change the preferred analysis is One that relates slmultancous superflclal changes by demonstrating that they are the consequences of a single change in the grammar of the language. 
Th1s solt of demonstration can give evidence to aid in the resolution of synchronic disputes at two levelis. First, It can show, that, of two, competing theories of gramar, one is inadequate when historical data are considered. An example of this type is Lightfoot (1974) in which Lightfoot argues that historiaal changes in the precursors of Modern English modals (e.g. can, could, may, might, wili) can be Insightfully described within the framework' of a 'shallow syntax' as In the Extended Standard Theory, whereas seven simultaneous changes must be regarded as only accidentally. occurring at the same time in a framework incorporating an abstract syntax-ifor instance, In the generative semantics framework of Ross (1967).

Second, the consideration of historlcal data can provide evidence to aid in the decision between two competing synchronic analyses of a given phenomenon. Lightfoot's. (1974) analysis shows that an explanation for the simultaneity of seven diachronic changes in modals can be máde upon 'the assumption that a syntactic category of 'modal' was created in the sixteenth century. Thus it provides an argument for including the category 'modal' in à synchronic description of Modern English--given that no further reanalyses have occurred, and there appears to be no evidence for any. Chomsky (1965) is an example of a synchronic analysis for Modern English proposing' one category for verbs and a separate one for modals. On the other hand, Ross (1967) 
presents an analysis of Modern English in which no distinc-'. tion in category membership. is made between verbs and socalled 'modals'; both. are in the same category--that of verb's. The historical evidence presented by Lightfoot supports the former (type of) analysis for Modern English over the latter (type), stnce the former allows a good explanation to be made for the dlachrontc changes observed in modals.

The study of diachrontc change in language can therefore provide evidence to decide between different synchronic analyșes o given phenamenon and between different theortes. of grammar. There 1s also another way in which the study.

$\therefore$ of diachronle change can contribute to the development of - a theory of grammar. One approach to the probler of 'explaining the facts of language use and acquisition is to develop a theory of grammar so restrictive that 1 it is possible for the child acquiring the language--or for the linguist-uto find only one possible grammar that is compatible with the language data avaliable. This means that the grammatical theory will specify a limited number of grammars as possible systems to underlie human languages. In so doing, the theory predicts what changes are possible in grammars; a given gramiar can only change to anotrer in the set ' 'of possible grammars spectfied by the theory. The study of - language change can provide a test for the correctness of these predictions; it can also suggest further restrictions on the theory. The development of a theory of grammar and 


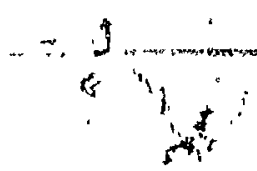

the study of diachronic change can interact in this way.

One example of a 'restifiction on the theory of grammar which the study of historical change "can provide evi-

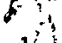
dence. Is the Opacity Principle proposed in Lightfoot (1974) and developed in more detail in Lightfoot (1976). This is a proposal that:

"...changes in valrious place's in the grammar may have the effect of making existing deep structure analyses more opaque to the language learner, harder to figure out: There seems to be a tolerance level for such exceptional behaviour or 'opacity', and when this is reached a radieal restructuring takes place and renders the deep structures more trarisparent, easier to figure out and 'closer' to their respective surface structures" (Light foot 1976, p. 6).

$$
-3
$$

The Opacity Principle will (ultimately) predict exactly how. much exceptional behavior--how many 'exception features'-can occur a re-stiructuring will be provoked. The Opacity Principle is illustrited in Lightfoot's . (1974) analysis of English modals. Lightfoot argues that In early Qld' English the precursors of Modérn English modals (henceforth pre-modals) showed the behavior of normal verbo-s. and should therefore be anialyzed as verbs for this period. By the end of the Middle English period, the pre-modais had "undergone four changes that made them exceptions to the normal behavion of verbs; that is, pre-modal's had four excep- - tion features by the end of the fifteenth century.: The premodals now-ióked llké a distinct class--one separate from that of verbs-and Lightfoot proposes that they were reanalyzed as a distinct category sometime in'the sixteenth $\Rightarrow$ 
century.' This proposal explains seven further changes in the (pre-)modals that took place in the sixteenth century; all seven changes follow from a re-analysis in which the category "'modal' was created.

The general explanation for these diachronic changes 1s, that pre-modals had become opaque as members of the categòry of verbs; and the four exeeption features proved to be enough to provoke a re-structurling of the base; the restructuring is evidenced by the seven later changes. The Opacity Principle is proposed as a principle of grammatical theory that restricts the set of possible syntactic components, but its effects can be seen most easily" in such historical change: It is through the study of individual cases of diachronic change that the functioning of the Opacity Principle can be studied, and in this way a determination of the tolerance level for opacity in synchronic gramuârs may ultimately be made.

A second area in which the study of diachronic change can contribute to the development of a restrictive theory of grammar is in ifs ability to provide evidence for the. autonomy thesis. Th1s is."..the claim that syntactic rules operate independently of considerations of meaning and use. This restricts the definition of a possible rule of grammar.9." (Light foot $1976, p, 7$ ). It is sometimes cialmed (e.g:. In Stockwell 1976) that syntactic change which is not caused by semantic and/or phonetic/phonological factors. 


of 'quantifiers' was established at the end of the sixteenth century:

It w1ll be seen that the behavior of the quantiflers ${ }^{2}$ themselves did not change in very radical ways, but rathery that changes in other categories in the grammar and the general clariflcation of distinctions between these categorles, caused quantiflers" gradially become isolated as a class. An analogy might be drawn to the old joke: If you volunteer, step forward; if all but one person step backward, the one person is as isolated as if he had stepped forward. In this respect the history of quantifiers provides a good example of the Opacity Princlple at work. The Independence of syntactic change from semantic factors is also demonstrated since the quantiflers themselves did not undergo any of the changes that isolated them, so it is hard to see how anyone could claim that this re-analysis was the result of semantic and/or phonetic or phonological factors. This re-analysis therefore is seen as providing evidence for the autonomy thesis as well as for the Opacity Principle.

The distinctive syntactic features of quantiflers in NE are the varlety of positions in relation to the noun modifled in which they can occur and their ablitty to stand alone as nouns. The possible positions for quantiflers are: 1) Preceding the modffled noun (and any adjective) 
as in 'all boys' 2). Predeterminer position as in 'all the. boys'. 3) Postnominal position as in thé boys all'

4) Foliowed by of and the modified noun phrase as in 'all of the boys' 5) What I will, contrary to current usage, cail postposed position as in 'the boys were all...'

Not all quantifiers exhibit all of these characteristics, of course. A syntaotic peculiarity of the class of quantiflers in NE that I w1ll not discuss is the fact that there are co-occurrence restrictions on the use of quantifiers with other quantifiers and with some adverbs. ${ }^{2}$

In $O E$, the quantifiers show the same positions and the same ablifty to occur alone as substantives:

1) Preceding the noun modifled as in 'all boys'

OE: cl000 Wi ealle wundela, genim pas wyrte" (The NE: Oxford English Dictionary (OED): under al1)

NE: 1873 Theognis bids his friend (Cyrnus) be as much as possible all things to all men (OED: all)

2) Predeterminer position as in 'all the boyș'

OE: 855 Ofer al his rice (OED: a.11)

NE: 1847 With all my heart, With my full heart (OED: $\underline{\text { all })}$

3) 'Postnominal position as in The boys all'

OE: 885 And ba scipo alle zeraehton (OED: all)

NE: 1782 The dogs did bark, the children screamed, Up flew the windows all (OED: all)

4) In OE, with a plural noun phrase in the genitive case; later followed by of and the noun phrase as in 'all of the boys'

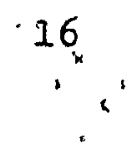


I

$\mathrm{OE}: \quad \mathrm{c} 875$

$\therefore \quad+4$

4

(OED: some)

NE: 1891 Higher up ...there arre some of the most

sublime scenes $I$, have looked on anywhere

"OED: some).

5) Postposed position as in the poyst were al1...'

$O E$ : al000 Hit is Adame nu eall forgolden (OED: alI)

$\mathrm{NE}:$ : 1850 Another is all plvolity (OED: all)

6) Used as substantives..

OE: , al000 AEIc hine sèlfa begrindep gastes dugèum

, TOED: each)

NE: . 1871 Each didmuch to...purify, the spiritual

self-respect of mankind. (OED: each)

Quantiflers were easy to find in all of these positions from OE to $\mathrm{NE}$, so I conclude that they were all productive positions throughout the history of English.

"I will first discuss the behavior of quantifiers in OE. I will show that, although their syntactic behavior in OE'Is very, similar to that in $N E$, this did not isolate them as, a class 1 in the earlier stage as 1 does now. This is because in $O E$, there were parallel constructions to those of quantiflers in normal adjective behavior, and so quantifiers fit quite"comfortably into the class of adjectives at this stage: Next I will trace the development of these parallels through $M E$ and later and show that several of them disintegrate towards the end of the ME period and in the following century, so that quantiflers--as adjectives--. have acquired several exception features. By 1600 , quant $1-$ 
flers no ionger look enough like adjectives, and the language resolves the resulting opacity by a re-analysis in which they are estaplished. As a syntactic category distinct from that of adjectives.

Inflection of adjêtives and quantifiers in $\dot{O E}$

In $O E$, adjectives are inflected for case, number, and gender.: There are two sets of inflectional endings, the weak and strong. The former is used when the adjective is preceded by a demonstrative" (se or pes) or possessive pronoun, when th modifies a noun in direct address, regulariy when it occurs in the comparative degree, and frequently when in the superlative degree; the stroing declension is used elsewhere (Kispert, p. 33). Quantifiers are declined exactly like adjoctives in $O E$, using the same inflectional endings and following the distinctions noted above for the use of the strong or weak set. of endings. Their occurrence in the weak form is rare because they do not occur in the comparative or superlative degree normaliy, and they do not appear to occur after demonstrative or possesive pronouns in $\mathrm{OE}$. This leaves their main use of the weak form as that in direct address, which is a comparatively rare use in 1 tsclf.

In fact, the use of quantiflers in the weak form is rare enough to cause some authors to state that they are exceptions (as adjectives) in.that they are always declined 
strong (Bright, p. Iv; Sievers-Cook, p. 215; Quirk, p. 31). But Campbell says "From adjectives of indefinite quantity, eall all, monig many, genōg enough, \&c., the weak forms. are naturally rare, but are used when syntax demands, e.g. pa monigan cyningas..." (p. 261). The reason for the confusion is undoubtedly the rarity of the weak form of quantifiers, as well as differences among grammarians in the specification of the conditions for the use of the weak and strong forms. Slevers-Cook, for example, says that the weak form occurs whenever the adjective is used as a noun (p. 215). But quantifiers occur in the strong form when used substantivally:

874 On allum pam pe him laestan woldon (OED: all) al000 AElc hine selfa begrindep gastes dugexum. (OED: each)

al000 ponne IC WInde sceal sincfaz sweljan of sumes
bosme, (OED: some) So Siévers-Cook concludes that quantifiers are-exceptions in occurring in the strong form when adjectives would use the weak. But Kispert gives an example of an (attributive) adjective used substantivaliy in the strong form: ac sé wonna hrefn füs ofèr fäèum [sceal] fela reordian (p. 43). Notice here that the adjective is not preceded by a demonstrative or posscssive pronoun. The fact is that adjegtives u'sed as substantives usually are preceded by a demonstrative--often enough so that Quirk says categorically: "Adjectives, used substantivally are preceded by a demonstrative: seo aełele "the noble (woman)'" (p. 88). However, 
although the weak form usually does occur in most of these cases, the rlght explanation for the weak form seems to be that 1t occurs because of the demonstrative or possessive and not because of the substantival use. The following quotation nicely illustrates the distinction:

Matthew xv.14 Se blinda, gyf he blindne laét (Keliner, p. 146)

Here both instances of the adjective blind are used as substantives, but the first one occurs with the demonstrative še and is thus in the weak form, while the second occurs without a demonstrative and is in the strong form. The syntactic Imbalance in weak and strong forms of quantifiers therefore actually follows from the semantic characteristics of quantifiers; their indefiniteness precludes the (frequent) use of demonstratives or degrees (with the exceptions of much, more, most; few, fewer, fewest). So quantiflers (as adjectives) are not syntactically deviant with respect to the strong versus weak distinction.

I conclude, therefore, that qufntifiers in oE act exactly like adjectives as far as inflections are concerned, and to that extent appear to-be members of the same category. Nouns and demonstratives, on the other hand, have slightly different inflectional endings, and thus look like distinct categories from quantifiers and adjectives in this respect. 
The type 'alí boys'

This is a common construction for quantifiers and other adjectives in $O E$, as in $N E$. The quantifier or other.adJective, is inflected to agree in case, number, and gender with the noun in $O E$; the strong form of the adjective or quantifier is used since it is not preceded by a demonstrative or possessive pronoun. This construction is exactly the same for quantifiers and adjectives; quantifiers look just, like adjectives when they occur' in it.

In fact, quantifiers look a bit more like adjectives when they occur in this construction in OE than in NE. Attributive adjectives in $O E$ and $N E$ can commonly occur with

- either a singular or plural noun--e.g., a/the black hole; black holes. In NE quantiflers differ from ordinary (attributive) adjectives in that most of them have severe restrictions on their use immedlately preceding singular and plural substantives. For example, each, every, and elther can only - occur before singular nouns, while many; several, and most can only occur before plural pouns. Quantiflers in OE are restricted in this respect tob, but apparently not quite as much; many and each could occur immediately before elther a plural or a singular noun in OE, for instance, (Jespersen VII, $12.5_{11}$; OED : many, each):

c893 haet Estland is swy maniz burh (OED: many) c1000 AElce wunde hyt zehaelep 


\section{The type 'all the, boys'}

Although in NE only quantifiers occurpin predeterminer

"position, in $O E$ there are several other types of adjectives that can occupy this position: \}

1) Kispert (p. 140) says that adjectives ending in -weard.

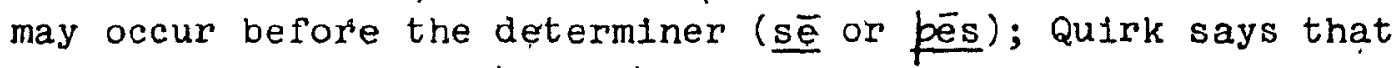
these adjectives usually precede tha demonstrative: on süxeweardum päem lande; of inneweardre his heortan (p. 88).

2) Kispert states that normally. sē, pēs and mIn precede a noun and any adjectives modifying the noun "...but a meta"thesis of positions also occurs: ...on sele päm hean" (p. 140). Mosse (p. 123) says: "Whe order "adjective +

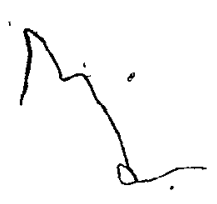
article (demonstrative, possessive) + substantive" that is still encountered in Lawman was undoubtedly a survival from OE;" he gives three examples from The Brut:

end $12 \mathrm{th}^{\circ} \mathrm{C}$ at aełelen are chirechen (Mosse, p. 123) end 12th $C$ mid deore mine sweorde (Mosse, p. 123) end' 12th C mld sele pan kinge (Mosse, p. 123)

I have been unable to find any further evidence about this type, and morè study is needed to decide this point conclusively. K1spert's and Mosse's statements do seem to Imply, however, that predéterminer position for attributive adjec- tives might have been a productive position in OE; if so, this type provides a good parallel for predeterminer position for quantifieŕs.

3) In $\mathrm{OE}$ possessive pronouns may precede the demonstrative and noun: haeled mín se leófa (Kellner, j. 138). Mustanoja 
says that this type (min se leofa (leofesta) freond) is common in OE $(p, 298)$.

Possessive pronouns in (sometimes called possessive adjectives) include mIn, pin, sin, uncer, incer, ürel úser, and éower. These possessivè pronouns are fully declined as strong adjectives to agree in number, gender, and case with the noun modifled. Other possessive pronouns are, his, hiere, and hiera. These are the third person possessives, and are not declined but remain invariant regardless of the noun modifled (Kispert, p. 92).

Since most of them are decilined exactly like adjectives, it seems that the possessive pronouns in $O E$ should be analyzed as adjectives. The third person possessives then represent invariábiè adjectlves like fela and unrim. As is shown in the examples above, the possessives can co-occur. with the determiner se (perhaps they also co-occur with pes but ' $I$ have no examples of this type), so should not be cate$\because$ gorizedias determiners. In $O E$ as in $N E$ e1their se or pes can occur in a noún phrase, but not both. Th1s restriction on co-occurrence is naturally handled by an analysis in which both are treated as 'determiners' and only one determiner

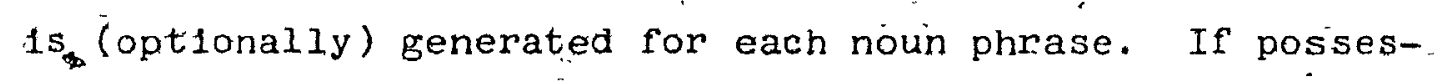
sives were treated as determiners a speciric statement of these co-oicurrence restrictions would have to be made--an expense to the grammar with no pparent corresponding gain.. If possessives are analyzed as adjectives, they can co-occur 
with other adjectives and with elther one of the determiners se and pes. Therefore, I propose that possessives ip $O E$ should be analyzed as adjectives, 3 and that the common $O E$ type 'min se leofa freond' is a parallel in adjectives to predeterminér position for quantifiers.

4) Numerals followed by adjectives in the superlative degree normally occur in predeterminer position (Kellner,

6. 110-1). The type one the best knight' occurs from the eleventh century on, while the plural type 'three the best. ointments' is attested since the tenth century Mustanoja, pp. $207-9):$

971 paer wáeron préo pa betstan ele (Kellner, pp. c1000 pis folc...haefp geworht ane pa.maestan synne . anda Gode pa lapustan (Mustanbja) p. 297) 1091 pas forewarde 3 esworan $x 11$ pa betste of pes 5 cyingè healfe (Visser, p. 226: OED)

The adjective 1 s normally, in the superlative in this type, with only one early example recorded with the adjective in the positive form (Mustanoja, pp.. 297-9).

There is some uncertainty over the interpretation of these types. Mustanoja argues that ane in these constructions 'is an emphatic, intensifying use found elsewhere in OE (pp. 297-8); while others argue that one stands for 'alone' or 'only,', a common use of tt in OE (Visser', p. 225). As for. the plural type, Mustanoja is uncertain whether or not a partitive meaning is associated with it (p. 300); Visser asserts that there is no partitive meaning--at least 
In the singular type--since the noun, is singular and not in the genitive ( $d .225$ ). Whatever the exact interpretation of these types 1s, however, they provide another case in which an adjective other than a quantifier characteristically occurs in predeterminer position, although it is restricted to the case in which a superlative follows. Mustanoja says: "This peculiar rhythmic arrangement, which probably has counterparts in most languages in the world, Is"responsible for"such common types as all the world, both the (se) boys, half:a bottle..." (p. 299). Both he and Kellner point out that a similar construction occurs in $O E$ with some and few :

Mid feáwum pam getrýwestum mannum ' (Mustanoja, p. 300) Heal fdene for mid sumum pam here on Norphymbre (Keliner, p. 110)

For this type to hold"as a parallel to quantifiers in normal adjectives, I must establish that numerals in $O E$ are in fact members of the category of adjectives.

Kellner says: "With the exception of hundred and thousand, which are always substantives, the numerals were in old English used both as a) Substantives (governing the geñ1tive case) and b) Adjectives". (p. 162). The first point to be made" here is that the "fact that numerals can function. as substantives, does not mean that they are nouns; تince adjectives in $O E$ can function freely as substantives the cardinal numeprals used as nouns' $\mathrm{ft}$ very well into that category. The second point is that Kellner is apparently 


\section{not correct in excluding hundred and thousand from adjec-} tivai use. The OED says for hundred: "In OE. sometimes

l used as a true adjective, elther invariable (like other - cardinal numbers above three), or declined in concora with its sb." And for thousand, the OED has a section for 1ts use as "adj. or quasi-adj., followed immediately by a plural (or collective) noun."

c975 Mið peningum twaem hundre 犭um (OED: hundred) cl000 Iob... waeron eft forzoldene... pusend jyme c1000 Mid twam hundred penezon (OED: hundred)

In each of these examples the numeral does act exactly like an adjective. OE had other invarlable adjectives (e.g. fela, unrim), so this invarlability alone i's not reason enough to discount hundred and thousand as adjectives. Also, their occurring as Invariable nouns is also exceptional (Bright, p. I11; Campbell, p. 285; Sievers-Cook; p. 238-9; Kispert, p. 116-7).

The first three cardinals, än, twëgen, prie, äre thé only ones to be inflected consistently as adjectives for

- each case and gender (K1spert, p. 116). Highér numerals can also be used as adjectives and can be declinéd as, well; 1

' aithough they are not usually inflected. But there are numerous exceptions in the Northern dialects (Slevers-Cook, p. 236$)$.
- Numerals can occur in the typical adjective position, beiween, the determiner and the modified noun:. 
c1175. Nu weren pas preo laze ze-writen Inne pa o\%re - table breode sunderlipes (OED: three)

c1275 B1-twene p1s twam volke (OED: two)

It seems, then, that in the simplest analysis of OE, numerais should be considered to be adjectives. This means that a fourth paraliel to predeterminer position for quantifiers holds in ÒE.

These four parallels--especlally the last two or perhaps three, which represent common and apparently regular types--support the proposal that predeterminer position for, quantifiers does not distinguish them from adjectives in OE-not, at any rate, as clearly as it does in NE. The predeterminer position of quantifiers in NE is unique and hèlps to define their distinctness as a class, but in $O E$ this, is not the case:

'The type 'the boys all'

The postnominal position of quantifiers in OE is a possible position for other adjectives as well as for quantiflers, so does not contribute substantially to the opacity of quantifiers as adjectives in OE. Qu1rk says (p. 88-9):

"It Is by no means rare to find modiflers in general (especially adjectives, and especially in poetic usage) following their nouns: freotoburh faegere 'Palr stronghold', wadu weallendu 'surging waters', niceras rilgene 'nine water-demons'. Fiven possessives and emphatic demonstratives can take this position: epeil pysne 'this country, wine mIn Unfertx' 'my friend, . $U^{\prime}$, gingran sinre, 'to' her handmaiden'."

Quirk also says that adjectives in -weard are frequently 
found following the noun modifled (p. 88). Klspert gives a few examples of postnominal position also: dryhten sinne 'his lord,' Nergiend üser 'our Saviour', (p. 140). And, finally, numeral adjectives are found postnominaliy:

Beowulf Uncer tweza (OED: two)

Beowulf Be baem zebrotrum twaem (OED: two)

Again, as with predeterminer position, postnominal position. does not distinguish quantifiers as a class on the grounds of exceptional syntactic behavior because demonstratives and attributive, possessive, and numeral adjectives can also occur in postnominal position. This shows a greater freedom of position for all noun modifiers in $O E$ that helped to keep quantifiers from looking too, distinct from other adjectival modifiers.

The type 'all of the boys'

In NE, most quantifiers can occur in this construction. In $O E$ the periphrastic genitive with of did not exist, but many of' its functions were handled by the fenttive'case inflection. So the same 'all of the boys' constructions could occur in OE; with the genitive, case of the noun in place of of plus the noun phrase. All of these constructions are : partitives, a common function of the genitive in $\mathrm{OE}$. Kispert (p. 122) says :

"This common use of the genitive indicates the whole from which a part is taken; the partitive genltive is often accompanied by fela 'much, many', ma 'more', a superlative, sum 'a certain (one)', some other indefinite pronoun, or a number." 
Keliner (p. 108) says more generally that the partitive genltive can be governed by nouns, adjectives in the comparative and superlative degree, numerals, interrogative pronouns and indefinite pronouns:.

Beowulf Aénigymbsittendra (Kellner, p. 109)

Beowulf An ae relinga, (Keliner, p. I09)

Beowulf Weor đmynda dáel. (Kellner, p. 109)

Beowuif máxma menigeo (Kellner, p. 109)

Beowulf nán gúrbilla (Kellner, p. 109)

Elene folca gedryht (Kellner, p. 109)

Elene arłeásra sceolu (Kellner, p. 109)

Anglo-Saxon Chronicle ehta hund mila (Smith, p. 241)

Anglo-Saxon Chronicle twegen gebrosa (Smith, p. 241)

Anglo-Saxon Chronicle scipu Deniscra monna (Smith, p. 241)

Anglo-Saxon Chronicle teopan dael his londes.

(Smith, p. 241)

These examples show that, rather than being a syntactic peculiarity of quantifiers, the use with the partitive genitive is a eharaeteristie shared by several classes of words

with a partitive meaning.

Since it occurs with superlative and comparative adjectives, the fact that the partitive gentive is used after quantifiers is not something that completely separates quantifiers from attributive adjectives syntactically. In addition, all and both do not seem to occur in this construction unt1l the end of the sixteenth century 4 (OED: all, poth; Jespersen VII, $\left.9.9_{2}\right)$; this means at least that quantifiers (Including $\underline{\mathrm{a} l l}$ and $\underline{\text { both}}$ ) were not a completely distinct and separate class, even within the adjective category, in OE.

Cardinal numerals are also found with the partitive genitive and this means that a good parallel in adjective 
behavior to the behavior of quantifiers exists in OE. I have argued that numerals should be considered to be members of the category of adjectives in $\mathrm{OE}$; the fact that both numerals and quantifiers can'take the partitive genttive strengthens the case that quantifiers, too, should be considered to be adjectives.

\section{The type 'the boys were all...'}

Quantifiers may occur in a postposed position in $O E$, as in NE; The OED says: "All adf.' Is often separated from the sb. which it defines, by an auxillary vb. or clause."
al000 Hit is Adame nu eall forgolden (OED: all)

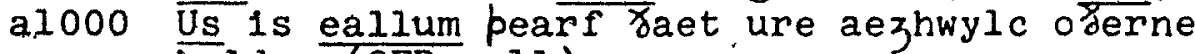 bylde (OED: all) c1000 H1z fearlia bezen on aenne pytt (OED: bo)

The quantifiers here are inflected in the strong declension to agree with the nouns they modify. W1th the elaborate - Inflectional system in $O E$ for adjectives, it is not difficult to locate the antecedents of eall, eallum, and bezen. Perhaps, invoking the relatively 'free' word order of $O E$, It could be sald that this postposition of quantifiers does not contribute much to the opacity of quantifiers as adjec"tives, as far as interpretation is concerned at least. But there:appears to be a more reasonable possibifity. \$n OE most adverbs aré morphologically derived from. nouns and adjectives. "Most commonly, advefrbs were speciaIIsed uses of an old adjective case-ending in -e that we can best call dative-instrumental (1t is concerned with, 
means and thence w1th manner)" (Strang, p. 272). 'An adverb. formed. from an adjective in this way is identical in form to the strong adjective in the feminine singular accusative, or in the nominative or accusative plural of any gender. This means that a postposed quantifier (which i's almost always strong), when moved off a noun that was in any one of these forms would look exactly like an adverb formed from the adjective ( $1 . e .$, from the quantifier). Another frequent source of adverbs in $O E$ is the use of any one of the oblique cases of a noun or adjective (w1th the neuter a-declension éndings). Quantifiers are no exception in this respect; they may be used as adverbs in their oblique cases Just like other adjectives. Kispert glves a few examples of each case (except. accusative plural, which he says is not recorded in adverbial use); his list includes gen. sg. ealles, dat. Instr. sg. ealle, accusatıve sg. eall and $\dot{\mathrm{g} e n o ̄ g}$ ('enough'), and dat. Instr. pl. miclum $(p p \cdot 80-1)$. So a quantifier moved off a houn in moṣt oblique cases would also look like a normal adverb. Note that the neuter accusative singular eall is Identical to the strong forms of the nominative singular form of all genders. Therefore, many quantifiers moved off nouns would look like adverbs in form, and in thelr postposed position would look like normal adverbs and not exceptional adjectives. Probably, however, such postposing would be malnly off the subject noun phrase (OED Implies that this is the usual case under the entry for all) and therefore 
the quantifler would very often be in a possible adverbial form.

It does appear to be true that the meaning of a sentence is often not more than slightly altered if at ali when a postposed quantifier is interpreted as an adverb. The OED says that a postposed quantifier may appear to refer to the predicate; e.g., in "'zion our mother is all wofull'... . a11, orlginaliy an attribute ór complement of zion, comes to be viewed as qualifying woful = altogether woful" (OED: . al1). Therefore interpreting a postposed quantifier as an adverb would normally not result in confusion or misinterpretation of the meaning of the sentence, and such an interpretation could survive in the language.

This (proposed) adverbial use of quantifiers has something of a parallel in numeral adjectives; neuter forms of cardinals can be used in multiplicative expressions as adverbs (Campbe11, p. 287):

c900 Lang scipu...pa waeron fulneah tu swa lange swa pa o犭ru (OED: two)

Adjectives and quantifiers used substantivaliy

A difference between quantifiers and adjectives in $\mathrm{NE}$ is that quantifiers, but not adjectives, can be used freely as substantives. But thls difference ded rot cxlet in OE. Kellner says:'. "Any adjectıve çan be used substantıvely" (p. 312). Strang says: "Finally, it must be said of the forms discussed here, and of all others which can be attri- 


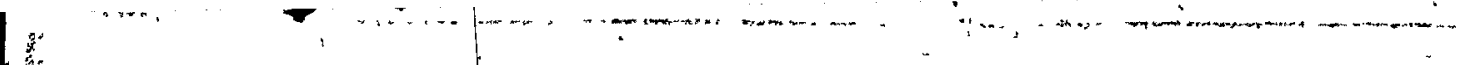

butive within the NP, that as loñg as they remalned highly Inflected they were free to act as heads. Demonstratives, numeral's, adjectives are all really pronouns as well; the traditional labels do not imply the distinctions we are now familiar with" (pp. 300-1). Adfectives may be used substantivalfy in $O E$ to refer to God, to man "and describing qual1ties of body and mind...used as well in the singular as in the plural, in the positive as well'as in the comparative and superlative degree" (Keliner, p. 146), to things and antmals, and to abstract 1aeas: 5

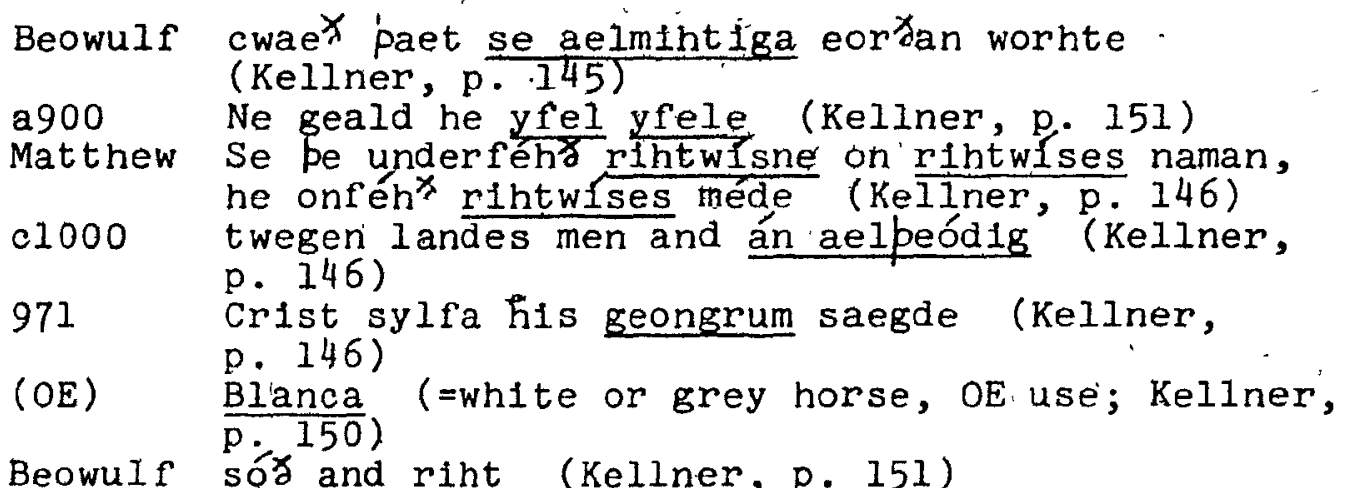

The substantival usage of adjectives was very free in $O E$, therefore; adjectives could be used substantivally for any type of referent, and this substantival usage was very frequent (Kellner, pp. 146-51). So In OE, quantiflers looked no different from all other adjectives: both could be freely used as substantives.

I have shown in this section that the syntactic functions and positions of quantiflers did not differ substantially from those of adjectives in OE. The two classes. 
behagve allke with respect to inflection (including the use of strong versus weak forms), with respect to prenominal ('all boys'), predeterminer and postnominal position, use with partitive genłtives, and use as substantives. I have also shown that the, postposing of quantiflers does not necessarily make them look like exceptions to normal adjective behavior because they can then usually be interpreted as normally formed adverbs. I conclude, then, that quantifiers should be considered to be members of the syntactic category of adjectives in $O E$; there is not enough motivation to complicate the grammar by setting up a distinct - category of quantifiers for this stage of English.

ME and later: Inflection of adjectives and quantifiers In late $O E$, final $-\underline{m}$ coalesced with $\underline{n}$ and in very early ME all vowels, in unstresised syllables were weakened to $e$ (Wyld, p. 239; Quirk, p. II). These phonetic changes resulted in the falrly elaborate $O E$ inflectional systems for nouns, adjectives, and demonstratives belng greatiy 'simplifled. The Northern dialects are ahead of the others in this change, but by the twelfth or thirteenth century it is generally true that only a versus -e Inflectional distinction exists for adjectives. The strong versus weak and singular versus plural distinctions are only partially.made in this system, and no'distinctions among cases are made. The strong singular form of the adjective has a null (b)' Inflec- 
tIonal ending, while the strong plural, and weak singular and plural all have an -e ending. This system, moreover, only applies to monosyliablc adjectives that end in a consonant (Mustanoja, p. 276; Strang, p. 210; Mosse, p. 64; Curme, p. 198). "These distinctions in the inflection of monosyllabtc adjectives are falrly well'preserved in the works of careful $14 \mathrm{th}$-century writers like Chaucer and Gower..." (Mústanoja, p. 276). All other adjectives are invariable in this period.

Quantifiers on the whole (except for the survival in some cases of a genitive plural, which will be considered later) follow the adjectives in the simplification to two forms (Emerson, xciv), although the weak forms are rare as In $O E$ and for the same reasons." The weak versus strong distinction becomes quite confused and irregular in $M E$, so quantiflers would not appear irregular in this respect at any rate. In OE some confusion is noticed by Quirk (p. 69) ahd Campbel1 (p. 261), but in ME this cionfusion appears to increase so that even in the earliest ME texts (e.g. The Peterborough Chronicle) the difference between the strong and weak declensions is suppressed and there is a tendency to use the adjective in an Invarlable form (Mustanoja, p. 276; Mosse, pp. 45, 90-1). So throughout the ME period, as In $O E$, no distinction betwey quantifiers and adjectives is made in inflection. Once final unstressed -e is lost towards the close of the fifteenth century, of course, 
quantifiers and adjectives are alike in not showing any (normal) inflectional endings. The final -e was often omitted in prose earlier and was probably not pronounced anymore, so'invariable forms for both quantifiers and adjectives should probably be considered to occur earlier in the period. (Wyld, p. 249).

"The type 'all of the boys'

In early ME numerals still occur with the inflecied partitive genitive:

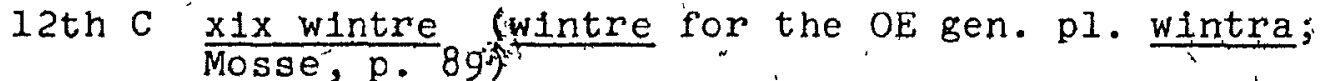
end 12th C fele hundred wintre (Mustanoja', p. 291)

But as the inflectional endings disappear, an appositive type of construction begins to appear with numerals. This. construction instead of the one with a partitive genitive occurs as early as the thirteenth century and becomes dom1nant (Kellner, p. 162; Mustanoja, p. 29i ):

c1340, These hundird shepe that were ther c1200 Man1 pusend hald saules (OED: thousand).

"The same sort of appositlve expression instead of a partitive'genitive begins to occur with words expressing measure: c1275/c1205 he...lette aenne drope blod

1362-93 a dozeinéchickenes (Mustanoja, p. 84) c1386 no morsel breed (Mustanoja, p. 84)

This construction is frequent in the thirteenth and fourteenth centuries. But the appositive construction suddenly begins to die out with nouns of measure towards the end of 
ME; It doès not appear in Caxton and hạs mostly disappeared by the end of the fifteenth century (Keliner, pp. 109-110; Mustanofa, p. 84). But it continues to occur throughout the period and into "NE with-hundred, thousand, (e.g.' 'NE a hundred sheep):

When the genitive periphrasis with of develops in the twelfth century, it is used with cafedinals throughout ME (Mustanoja, ;p. 79-80):

al225 fff and sixt1 hundred of hepene monnen

c1386 of ladies foure and twenty (Mustanoja, p. 80)

1390 of smale whieles twelve (Mustanoja, p. 80).

Sometime between the ME and NE period the of periphrastic genitive ceased to occur with smaller cardinals, but con- ' structions ilke hundreds of men," a-bushel of grain are still common constructions on into NE.

In early ME quantifiers occur with the inflected partitive genitive; when the of-periphrasis develops they begin to occur with that construction. (with" the exceptions of a11 and both):

c.175 Ga...per ent of pine cunne $11^{x}$ in (OED: any)

c1200 Ne chaes himm nohht te Laferrd Crist Till nan off hise posstless (OED: none)

c1200 Summe off ure little floce (Morris; p. 139)

c1205 Ne minten heo...heore nenne Lcl275. none of :

cl220 Zam] adun bringe (OED: none)

c1386 Ever 1ch of you schul brynge an hundred knightes (Morris, p. 191)

c1386 lle...maked ech of hem to been his thral (OED: each)

. 1388 Thei token éueryche of hem a peny (OED: every)

So in ME through NE quantiflers have, parallels with numérals 
and with nouns expressing measure; and this characteristic of quantiflérs remains a reason to regara numeral adjectives and quant1fter's as members of the same category.

\section{The type the boys'all'}

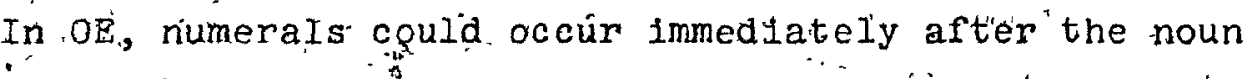
modified. This use seems less frequent $1 \mathrm{n}-\mathrm{ME}$; the $O E D$ has the last example for three in this position as the following:

al300 Flue thossand men... he Fedd wyt fiue laues $\therefore$ and fisses thre (OED: three)

This position is still used archalcaliy or poetlcally; when It ceased to be a productive normal position for"numerals; one adjectival parallel for quantifiers was lost.

The characteristic position for adjectival modifiérs In $O E$ was prenominal although this was by no means without exceptions. $\therefore$ In ME the postrominal posttion becomes a productive one for adjectives as is shown by the fact that all new borrowings come in as postpositives. "In this period. most adject1ves aan occur as pre-and post-nominals" (ilghtfoot 1975, p. 205). This means that with regard to the postnominal position (and the ordinary prenominal as in 'ali boys'; of course) quantffiers look like adjectives in $M E$ as long as this freedom in position lasts. But when, by the sixteenth contury, prenominal position is $\$$ tandurd, quantifiers are exceptional in that they alone can occur in postnominal position. By this tyme no other type of'modifier "can' (productively) occur in this position, so quantifiers are 
1solated as a class in this respect, and the first exception feature is added.

The type 'all the' boys'

Four parallels to predeterminer position for quantifiers were suggested for OE. The first (adjectives in -weara) and third types (possessive pronouns) do not seem to survive In this position after the $O E$ period in normal use.

The second proposed parallel to predeterminer positian for quantifiers was with ațtributive adjectives. Mossé (p. 123) points out the 'dear my lord' type in Shakespeare as the last survival of this type:

\section{Dear my lord (Abbott, p. 25)}

1605 Gentle my Lord (Jespersen II, 15.16)

In fact, the normal use of an attributive adjective in predeterminer position may be, said to have died out prior to Shakespeare's time. Both Jespepsen (II, 15.16) and Abbott (p. 25) suggest that In' the Ellzabethan address good my lord, my lord has, became a sort of compound like the French monsieur ior milord. Under this interpretation these examples In Ellzabethan English represent a frozen form, and not the normal usé of attributive, adjectives in predeterminer posttion. Jespersen (II, 15.16) says that the 'dear my lord' "form "...was then extended to similar groups" and gives the following examples:

$1588^{\circ}$ sweet my childe (Jespersen II, 15.16)
1588 good my glasse (In addressing the mirror;
, Jespersen II, 15.16 ) 
It seems that by-this time the form was only used in direct address; thus the Eldzabethan use was a very limited ore, and predeterminer pósition for adjectives may be said- to have died out earlier. The word order found in NE (my good lord) was also-found in Ellzabethan English (Jespersen II, $15: 16)$. At any rate, whether 1 d died out with the El1zabethans or before them, this paraliel to predeterminer position for quantifiers no longer existed by the beginning of the seventeenth century.

The 'one the best 'knight type' in OE was discussed earlier. It occurs throughout ME as well; Visser says, that it occurs rather frequently in the fourteenth and fifteenth centuries ( $p .225$ ): In adaition, this construction without a following noun is recorded in ME. VIsser gives as earliest examples Chaucer:

c1368 I am so l1tel worthy, and ye so good, For ye be oon the worthiest on lyve (V1sser; p. 225)

' c1374 For I have falsed oon the gentileste... and oon the worthieste (Visser, p. 226)

Mustanoja says that this construction " $\therefore$ becomes stereo-

- typed and begins to deterioratie before the end of the ME perlod" (Mustanoja, p. 299).

'The types 'one the best,' 'one the best knight' and

'two the proudest knights' all die out in the Eilzabethan

age. Visser gives as last examples:

1611. He 1s one The truest manrier'd (V1sser, p. 225)

1590-6 He 1s one the truest knIght alive (Visser, p. 226)

-1590-6 His stature a1d exceed The hight of three the tallest-sonnes of mortal, seed (V1sser, p. 226) 
Mustanoja, Visser, and Kellner all agree that these types die out in the Elizabethan era (pp. 297-300,'p. 225, and pp. 110-1 respectively). Whatever the reason for th1s construction dying out, the fact that it did means that pre-

i determiner position is now occupled by quantifiers alone. This means that another exception feature is added to quantifters sometime between the late ME period and the end of the sixteenth century.

The type 'the boys were all...'

. In early $M E$, as in $Q E$, most adverbs are morphologicaliy derived. In $O E$ the most common ending was the old dativeInstrumental -e added to adjectives, and 1 t is still used In ME (Strang, p. 272). Before the simplification of adjective inflections to $-\underline{e}$ and $\varnothing$, this ending distingulshed an adverb from an adjective (in most of its forms). But when adjectives are simplified to two forms, adjectives will very often end in -e and be indistingulshable from the adverbs formed from them in this way. And also, when final -e 1s lost, these adjectives and adverbs w111 st111 be Indistingulshable from each other. This leads to confusion in their use:

c1205/c1275 for his wel dede (Mustanoja, p. 649) end $14 \mathrm{th} \mathrm{C}$ the condicioun of mannes goodes...ne last nat perpetuel (Mustanoja, p. 648)

Adfectives are often used in adverbial function in $M E$, and the use of adverbs instead of attributive adjectives--though 


\section{$-\cdots$}

rare in earl $\mathrm{ME}-$-is frequent in late $\mathrm{ME}$. This confusion and use of one form for the other is Increased by the existence of areas where adjectival and adverblal functions almost overlap--e.g. predicate adjectives and modal adverbs (Mustanoja; p. 314):

cI386 he nas nat right fat, I undertake, But looked h! holwe, and therto sobrely (Mustanoja, p. 314)

Under these conditions, the postposing of quantifiers is not a use that would make them look exceptional, or distinct from adjectives: they, will simply look like the fairly frequent type of adverbs that used to end in -e and are now identical to their corresponding adjectives--unchanged adverbs.

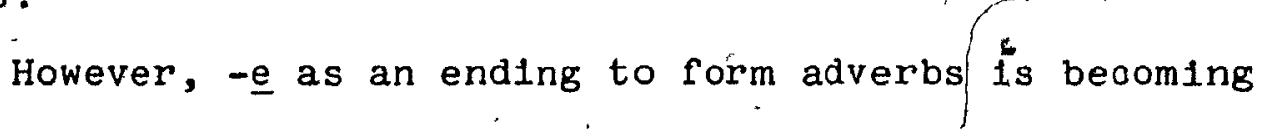
Inact1ve by about 1170 , and the adverblal ending -11ce ( $-\underline{y}$ in NE) is highly productive. 6 The use of -1ice Increases greatiy within the ME period (Mustanoja, p. 314) and becomes the regular method of forming adverbs.

Strang says that throughout the history of Engl1sh there has been uneasiness about adjectives and adverbs 1dentical in form, and that there has been a steady progress from the plain, or unchanged, type to the type in - ly-that is, progress towards making a clear distinction in form (p. 273; Curme, p. 335, agrees). The growth of the -ly form enables this distinction to be made.

Evidence of the growing tendency to make a clear dis- 
tinction betwèen adverbs and adjectives by using - iy as the distinctive adverbial ending is the tendency to use it even, on adjectives that already end in $-1 y$. The OED (-Iy) states:

"It was, down to the 17 th $c$., somewhat frequently attached...even to adjs. in -1y, as earlily, godlily, kindlily, Iivelily, lovelily, statelily; but these formations are now generally avolded as awkward..."

In addition, Jespersen says that - ly was originally only added to words of native orlgin, but began later to be used with French loans as well. He gives as examples princely and scholarly (Jespersen VI, 22.93), wh1ch the OED dates from a 1548 and 1598 respectively.

So from late ME, there is a growing tendericy to make unchanged adverbs distinct from adjectives, and it is done by the increased use of (only) one adverblal ending: - Iy. In the middle of the sixteenth century it looks as though this tendency reached a peak. The use of quantifiers in, postposed position is contrary to this tendency, and it seems reasonable to propose that towards the end of the sixteenth century a third exception feature is added to quantifiers as adfectives.

This part or the history of adverbs in English is an example of a principle of historical change proposed by Lightfoot (Personal communication): that languages practice. therapy rather than prophylaxts. In OE advents were distingulshed from adjectives by their -e ending. Inflectlonal 
endings were later. leveled to -e, although that change made adverbs indistinguishable from adjectives. Then the language extenifed the use of the -lice form to remedy the problem thät it had created.

Adjectives and quantifiers used substantivaliy

The $O E$ freedom in the use of adjectives às substantives continued on through ME as well: "In ME adjectives could be used substantively without any restriction and they rer malned, generally, Invartable" (Mossé! p. 91). They could. be rused in the singular or plural to refer to persons, to animals, to things, and to abstract ideas:

end I4th C that fre
end 12th C pe fremede
end 14 th C pe broun
end 12 th C pa aexelen
mid 13th C heore hot
end l2th C unholde
'that noble (person)'
'the strangers'.
the browns, the brown beasts, stags'
'the noble (ones; $1 . e$. deeds)
'their hót (ness)'
'the enemies'
(All quotations are from Mosse, p: 91)

The substantival use of adjectives is frequent in ME, as 1t was in OE (Emerson, cxx1; Mustanoja, p. 642) and is at least partiy due to the same factors, in addition to being a survivor from $O E$ : "The distinction between nouns and adjectives has never been a very sharp one, and the "conversion of nouns into adjectives and vice versa is therefore a natural process" (Mustanoja, p. 642). Quantifiers In $M E$ continute to be used freely as substantives, as they haye been throughout the entire history of English. 
So in early $M E$, as in $O E$, both adjectives and quantiflers have the ability to occur freely as substantives, and what is a peculiarity of quantifiers in NE is not one in , the earlier periods. But In late ME the substantival use of adjectives begins to occur less frequently and less , freely according to Strang (p. 205):

"Adjectives in the late $14 \mathrm{c}$ could freely be used as head-words in reference to persons or things, singular or plural. But this usage had really become anomalous with the virtual, and in the 150. total, disappearance of adjectival inflections for number, and the growing "pronominal distinctions, for human/non-human gender... By the end of the period [1570] exceptions can be found (cf. 286), but something approaching the present restrictions on adjectives as head-words is in operation."

The use of an adjective substantivally with a singuIar réferent falis into disuse in late $\mathrm{ME}$ and is only occasionally found after the ME period (Mustanoja, p. 645; Kellner, pp. 147-8). The substantival use of an adjective

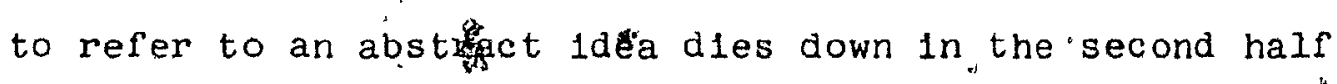
of the fifteenth century and the first half of the sixteenth century, and although it is revived by Elizabethan authors, 1t dies out with them (Kellner, pp. 151, 154).

When the free substantival use of adjectives disappears, the distinction between the category of nouns and that of adjectives becomes much clearer, and quantiflers in substantival use look l1ke nouns. Jespersen says that "The formal distinction between substantives and adjectives is more pronounced in English than in any other language of 
the same family;..." (II, 8.13). Thls distinction (in $\mathrm{NE})$ is the presence of the quite general $-\underline{s}$ plural and genitive inflection for nouns. Once a word occurs with this Inflection, Jespersen says it is a noun (II, 9.21). Although - - was not a plural marker for adjectives, it spread in $M E$ to some adjectives (as well as to a great many nouns which had had different plurals in $O E$ ); although only the strong. masculine and neuter singular adjective had a genitive in -es, this nominal genitive was gradually extended to adjectives used substantivally, which then virtually became substantives (Jespersen II, 9.51). 7 Th1s is more evidence of the growing tendency to interpret adjectives used substantivaliy as nouns.

The growth in the use of the propword one is part of the same increasing distinction between adjectives and nouns as the decrease in the use of adjectives as substantives.Following are some of the examples proposed as the first cleagr instances of the propword one:

1338 a moche felde; so grete a one never he behelde (Strang, p. 271)

1380 Wan he was armed on horsebak, a fair knyz.t a was to see, A lolif on wyp oute lak, bope strong \& fers was hee (Kellner, p. 161)

Môsse'agrees with Strang and Kellner that the use of the propword qne occurs from the middle of the fourteenth century; at that time it was still superfluous (Mos\$e, p. 91). Jespersern (II, Appendlx X) gives the following as an approximate chronology for the development of the propword one: - 


1300 a good one
1400 the good one
1550 never a one, such a one, (the) good ones
1600 one good one
18 th c that one, a silver one
$19 t h \mathrm{C}$ the one (we) preferred, those ones, ane
to keep companx, the ones that..., my one

There are various explanations about the reasons for. this development. It allows the distinction of singular versus plural to be made (one/ones), and as evidence for the importance of this function there is the fact that in early quotations using the propword the plural is more frequent (Jespersen II, 10.82). The propword also. fills a position in the sentence that is otherwise lacking (a noun became an obligatory part of a noun phrase); this is something like the use of 1 t and there to fill the subject position (Jespersen II, 10.12). Tied in with the development of the propword are the loss of inflections and the relative 'fixing' of word order in ME. It is in the fifteenth century that the use of 1 t and there to fill the subject position 1s well-established (Strang, pp. 96, 211), so fllling the noun slot in a noun phrase fits in well with the time of that development.

The important thing to notice here is that it is in the sixteenth and seventeenth centuries that the use of the propword seems completely established: "Examples abound. In the 16th and following centurles" (Jespersen II, 10.32). So nthe quantifier adjective, which is still completely free to stand alone as a substantive, has an exception reature 
by this time.

An interesting observation is that some of the quantiflers could occur with one from OE onward; this was or $1-$ ginally the numeral one, but as one developed its indefinite function, could be interpreted as the indefinite or, finally, propword one instead (Jespersen II, 10.22):

971 AEt aezhwylcum anum para hongap leohfaet

c1200 patt $11 \frac{\text { each }}{1 \mathrm{c} a n}$ shollde witenn wel (OED: each)

a1225 of euerich one (Jespersen II, 10.22)

c1225 Blesc1t ou mid euerichon of teos gretunges (OED: every)

c1250 $\mathrm{HIm}$ and $\frac{11 \mathrm{c}-0 n}{\mathrm{his}} \mathrm{kamel}$. Wiz watres drInc.

ghe quemede wel (OED: each)
c1250 par-inne is monyon hungri hund (Visser, p. 79)

This use may have contributed to retarding the re-analysis of quantifiers by decreasing their opacity as adjectives.

\section{Quantiflers as a olass}

As was mentioned earlier, quantifiers, numerals, and a number of nouns of measure all could take the partitive genitive in $O E$, and then the of-periphrastic genitive in ME. It seems possible that in the earlier stages this was a genuine 'semant1c' partitive--a part of a whole was referred to. The fact that all and both do not seem to occur with elther a partitive genitive or an of-periphrasis unt11 much later adds support to this possibility. Jespersen says that neither all of them nor both of them is found in Malory (according to Baldwin), but from Elizabethan times these expressions become frequent (Jespersen VII, $9.9_{2}$ ). 
The OED has as first examples:

1593 Yea, all of them at Bristow lost their heads (COED : all)

1590 I am sure you both of you remember me (OED: both)

The OED (al1) says that the all of construction is "...comparatively modern, and is probably due to form-assoc. With none of, some of, little of, much of, few of, many of" and calls it rare except with pronouns. For both the OED says:

"Both of is now used before pronouns and pronominal words, Instead of the simple both...The use with a sb., as 'both of these arguments', is colloquial, but scarcely ever occurs in 11terature." This may be considered evidence that at this time these quantifiers were considered to be part of a class and the construction with of was extended to them for that reason.

Evidence of confusion before the re-analysis

Quantiflers have four exception features towards the - end of the sixteenth century: their.uses in postnominal and in ptedeterminer positions, their postposing ('the boys were all...'), and their free use as substantives. There is evidence that there was some confusion as to the status of quantiflers in the second half of the sixteenth and first half of the seventeenth centuries, which would be expected in a class whose category membership is opaque.

In the second half of the sixteenth century, quant1fiers begin to occur with the $-\underline{s}$ genitive that shows that 
they are being interpreted as nouns. Jespersen (II, 9.55), says: "The genitive plural is practically never found in those cases in which adjectives and adjectival pronouns can stand alone as principals, though Shakespeare has in manies eyes ... in manies lookes..." More examples:

1509 and none's death discuss (Curme, p. 174;

Curme's apostrophe in none's)

1548 If eythers worke (OED: elther)

1565 sommes consciences OED: some)

1580 as great delight in thy company as ever I did in anyes (Curme, p. 174)

1591 as eithers way them led (OED: either)

1593 of elthers colour was the other, (OED: either)

1597 somes lot (OED: some)

1598 of manles ouerthrow (OED: many)

c1600 they are both in either's powers (Schmidt: e1ther; Schmidt's apostrophe. Schmidt gives

$1616^{\circ}$ a number of such examples)

1653 for somes unquietness (OED: some)

1675 to somes understanding (OED: some)

1715 both's witnesses (OED: both)

1823 some's Self-love (OED: some; quotation is from Byron)

The OED (some) says the possessive form of some is now rare. "In early mod.Eng. sometimes inflected as a sb., with genttive both's" (OED: both). OED says of elther: "...formerly sometimes inflected in genit."

More evidence of confusion as to the status of quantifiers is the existence of the following type of construction in which they occur after of, normally only a noun position:

1489. Whether of the both il shall loretume (OED: both)

1544 We be borne for neither of bothe (OED: both)

1584 The covetous man is the worst of both (OED: both)

1588 Ne1ther of either, I remit both twain (Jespersen VII, $17.8_{1}$ ) 
1621 W1ves were taken in Israel by b1ls of Dowry, and solemne espousals; but concubines without elther of both (OED: either)

1667 Either of both abhorreth one the other.

(OED: b.oth)

The last example may be archalc; my other. examples are in the range of' 1540 to 1620 . These constructions are occurring at exactly the time I propose the category of quantiflers as distinct from that of adjectives was being established, and the quantiflers inflected in the genitive like nouns in the previous set of examples occur during the same time span. Since adjectives had begun to lose their ability to, occur, freely as substantives, quantifiers began to look like nouns rather than (or in addition to) adjectives because of their continuing ab1lity to be freely used substantivaly. By the middle of the sixteenth century quantifiers had four exception features and their categorization as adjectives was becoming opaque enough so that, it seems, they were beginning to be interpreted as nouns (probably in addition to belng considered adjectives because of the other constructions in which they also occurred). Things could have continued in this direction, so that they became full nouns, but instead it appears that a reanalysis took place and a separate syntactic category of quantiflers was established.

\section{Changes caused by the re-analysis}

In earlier periods of English, quantiflers could occur preceding a pronoun, OED says for al1: "... with a pers. 
or rel. pron. (In the nom. ail was formerly often prefixed; e.g. a ail we, for which the "mod. usage is we all, or all of us.)" Th1s appears to be a very frequent construction in $M E$, Judging from the numerous examples of 1 t given by $N E D$ :

cl000 Ealle hi sind on Godes jesihYe (OED: all) al225(?alz00) purh heore vuelé raede, beien heo beo: daedde (MED: bō)

c1275 Summe hi weren wyse, and duden al bi his rede (OED: some)

1382 Alle wee as șhep erreden (OED: all) c1475 (ci445) Resoun.,.allowip bohe hem to be doon. (MED: böthe)

al 470 Here be within this castell thirty ladyes, and

1593. $\frac{\text { all they be wydowys (MED: al) }}{\text { as all you know (Schmidt: }}$

1594 Both they Match not the high perfection of my loss (Abbott, p. 162)

1602 Into the madness wherein now he raves And aII we mourn for (Abbott, p. 161)

1611 AIle we like sheepe haue gone astray (OED: al1; quotation is from Authorized Version of the Bible)

The 1611 example is from the Authorized Version of the Blble, which Strang (p. 140) says is almost entirely in the language of Tyndale (1525); I have no other examples later than Shakespeare.

Mustanoja says: "All, followed by a personal pronoun occurs fom OE down to earlier Mod. E. "ealle hi sculen. puder cuipe (Poema Mor. 174)" (p. 213), but gives no later example. Relying on Mustanoja's statement and on the range. of the examples I have found, I assume that this type died out by the beginning of the seventeenth century, and thus just about at the time of my proposed re-analysis of quant 1 fiers. 
In Shakespeare this type may have already been marked and used only for emphasis; this is what Abbott (p. 316) seems to Imply: "So "we" is emphatic in, "all we like sheep have gone astray," and in Hamlet, 11.2.15l, in both cases, beciuse of antithesis.

"Into the madness wherein now he raves

And all we mourn for." (A'bbot's 's emphases)

At earlier periods, this use may have been felt as a substantival use of all in apposition to the pronoun we, but when other appositive types died out (a bushel venym) it may. have been felt as anomalous and given way to all of us or we all. Otherwse it may have something to do with the establishment of the of-génitive following all and both. I have no real explanation for this construction dying out, . but include examples of 1 t because of its possible relagtion-, ship to the re-analysis of quantifiers, especialiy in view of'its dying out at the same time as the re-aralysis.

A construction in which"a pronoun and a quantifier. both inflected in the genitive, modify a noun, occurs from - the beginning of' the ME pertod:

$$
\begin{aligned}
& \text { a1126 here elces riht hand (MED: éch) } \\
& \text { c1175 heorebelra gast (OED: bo) } \\
& 1377 \text { her botheres myztes (OED: both) } \\
& \text { c1387-95 at oure allei cost (MED: a1) } \\
& \text { a1450 for herebeyre lou (MED: bo ) } \\
& 1513 \text { our alleris offence (OED: all) } \\
& 1536 \text {. your bothe Soverelgne (OED: both) }
\end{aligned}
$$

The MED (al, bothe) says that oure alre $(\underline{\text { s }})=$ of all of us'; ' her botheres $=$ 'of both of them.' 
There are numerous examples of this construction in ME (I have collected just over one hundred of them), all. the way up to 1500. Although I have only two certain examples after 1500, as with the last type I am sure that it -did not disappear instantly after that date; the problem undoubtedly lies in the difference between a good source for ME--the MED--and a less extensive source for data after the ME period.

It seems strange that a genitive plural marking should exist at so late a stage as the end of ME, but all of my examples show some sort of inflection, and almost all show a clear survival of an old adjectival genitive plural. Mustanoja says that the inflectional genftive plural of all Is current in alI dialects in ME in a partitive sense 'of all' and is particularly common after a posisessive (p. 213). The MED says "... In ME, the gen. [of bö] occurs only in the phrases oure belre etc." The OED (all) says about. this construction with all: "Later northern witters, to whom the -er had no Ionger a genitive force, âded a second possessive ending, making alleris, alders, althers." Another unusual fact is that all and both are the most frequent quantiflers in this type, although they do not otherwise occur. with a gentitue in the history of. English and only begin to ocour with a rollowing of plus noun phrase at the end of the sixteenth century. The addition of an $-\underline{s}$ ending seems to Indicate that these quantiflers were felt as nouns; or 


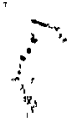

perhaps they were felt as equivalent to the possessive pronouns.

The construction without a following noun also occurs In ME; MED lists comparatively few examples:

all21 Ealre b1scope curs he habbe, and here ealre pe her be ge witnesse (MED: al)

?c1200 Ezjperr bezzre wass off sopfasst lufe filledd (MED: e1ther )

When it occurs without a following noun, the order to elther with the quantifier preceding or following the possessive. the OED says (for elther) that this use survived until the seventeenth century.

The construction with a noun following appears frequently later, although in a somewhat different form:

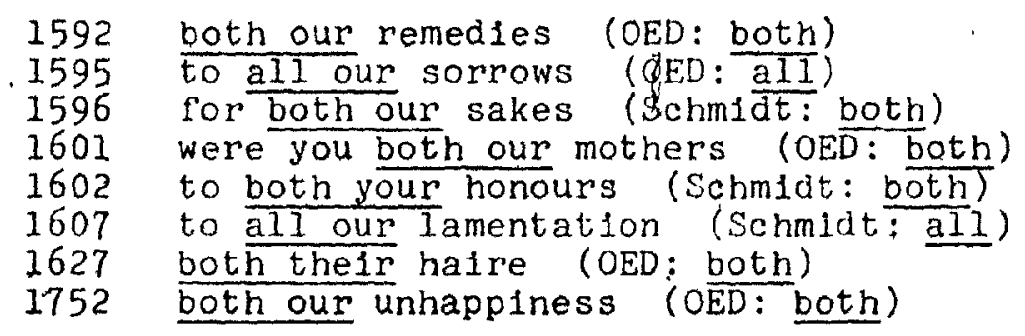

With only a few exceptions, ${ }^{8}$ all my examples of the 'heora belre gast' type have the possessive pronoun occurring first and the quantifier following with some sort of geltival inflection. In addition, in the large majority of the cases the following noun is singular. However, in all the examples--without exceplion--that I have found from 159? on, the quantifier precedes; the noun is either a sort of collective (e.g. unhappiness, haire, lamentation) that does not. normally occur with a plural $-\frac{5}{4}$ ending, or is a regular 
plural. The plural occurs even where a singular would be expected because the quantifier undaubtedy modifies the pronoun instead of the following noun (e.g. the quotations from 1595 and 1601 above; Jespersen VI, $\left.17.6_{2}\right)$. The following later quotations illustrate the same point:

1738 one brlmmer to all your healths (Jespersen VI, 17.62 )

1830 a sister died in both our infancies (Jespersen VI, $17 . \overline{62}$ )

1915 I think she's been pulling both our legs successfully (Jespersen VI, $17.6_{2}$ )

Jespersen gives some twenty-five other modern examples, and In all but one the noun is in the plural:

$1710 \mathrm{Dr}$. Sw1ft is all our favourite (Jespersen VI, $\left.17.6_{2}\right)$

I have fourteen examples of the liater type ('both our mothers') from Shakespeare's, works alone (that have been quoted by Schmidt, OED, or Jespersen), so this is apparently a relatively frequent construction in spite of a dearth of examples from the sixteenth century. A sudden and fair1y arastic change in a common construction must be explained. Th1s change occurs at exactly the point at which I claim that quantifiers were established as a category distinct from adjectives. The shift in order and in the number of the following noun can be explained in terms of the re-analysls or quantifiers.

The first thing to be noticed is that in the earlier type the quantifier looks as though it is in the typlcal adjective position, following the determiner and preceding 
the noun. In addition, the construction looks something like the older construction in which two adjectives modifying a nown would each be inflected; this is especially true for the later part of the period in which this construction occurs when the inflection may no longer be recognized. as being genitival. A reasonable explanation seems to be that these old constructions were idioms or frozen forms--by the sixteenth century at least--and that they ceased to occur when, the re-analysis of quantifiers took place because their construction, no longer understood a's genitival, made them look like adjectival uses which were anomalous after quantifiers were established as a category distinct from adjectives. One other possibility is not unIlkely: especially because of their - $\underline{r}$ ending (shared by the majority of the examples), they may have zbeen re-interpreted at some time within the ME period as being adjectival possessive pronouns on an analogy to our, the1r, etc. (This $-\underline{r}$ is the normal istrong $O E$ genttive plural inflection for adjectives.) If this were the case, again this adjectival. interpiretation would be expected to disappear once quantiflers are a distinct category.

In the earlier stages of English, quantiflers would be generated under adjective nodes. This means that they would' be on a 'coordinate' level with other adjectives and with the noun modified. After the re-analysis of 'quantiflers took place, the change of singular to plural in the following 
noun can be explained if a well-established structural anaIysis of quantiflers is adopted in which the quantifler occurs, on a higher, separate node:

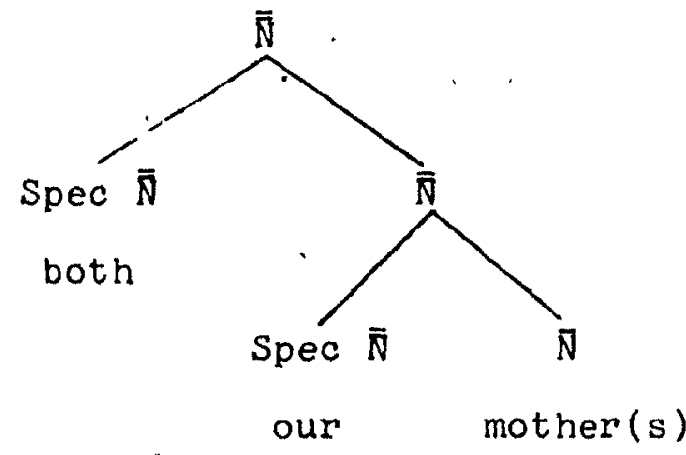

In this structure, the quantifier 'modifies' the whole" noun phrase our mother, and cannot be taken only with our. The quantifier both requires a plural noun when it occurs in the 'all the boys' type. For all, elther a plural or singular noun can occur in this construction; perhaps plural is more common. This would explain the plural.makker on the noun even when a singular form 1s actually the one required by the meaning.

It is tempting to think that this raising of the quantifler would also account for the loss of the 'all we' type; In NE a pronoun not immediately dominated by ' $S$ ' normally cannot occur in the 'nominative' case, so this would explaln why the 'all we' type 13 lost. llowever, It does not explain why the pronoun cannot then occur in the oblique case: *All us like sheep have... 


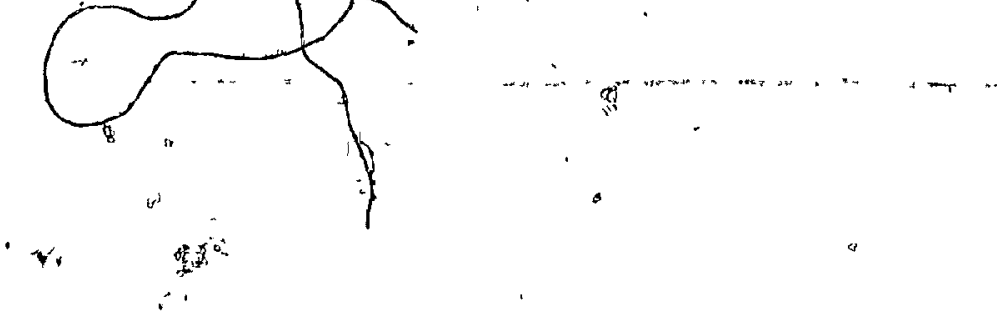

- There are two more changes that tók place at about the time of the re-analysis of quantifiers which can be explained by 1t, and which therefore lend some support to its existence.

In NE quantifiers cannot occur freely in confunction $\therefore$ with each other, but in earlier stages of the language thelr use seems to have been freer in this respect:

c1275 Mid childe hil weren bope two (OED: both)

c1420 pey weron as bleynd all bothe, y wys, as ever was ony stok or stoune (OED: all)

1413 The scorpyon...byteth and stynseth bothe two at ones (OED: both)

1561 They all endeuor...to kepe'still eyther bothe kingdome safè (OED: either)

1571 Yet would he retain with hym still Silan and Sasilas, all both Lacedomonians (OED: both)

1600 To endeavour and strain themselves, both all and some (OED: al1)

1600 Both find each other, and I lose both twain (OED: both)

I do not have any later examples like these; the only others I have found are the following:

1621 Wives were taken in Israel by bils of Dowry,
and solemne espousals; but concubines without and solemne espousals; but conc
e1ther of both (OED: either)

1667 Either of both abhorreth one the other

These two quotations are of a somewhat different type than those in whtch two quantiflers occur adjacentiy, and may be ruled outo in NE by a semant1c rulc rather than by a syn84 tactic one of-co-occurrence; I wlll not explore thIs problem further.

My examples of quantiflers used freely in conjunction with each other are al in the sixteenth century or earlier-- 
perhaps in the seventeenth century or earlier, if the last two quotations given above are of the same type. These data are compatible with the proposal that quantifiers were treated as normal adjectives earlier, and, in accordance with the uses of that category were able to be used in conJunction with each other freely- $l i k e$, for example, the big bad wolf. More study is certainly needed to establish this point, but if it can be supported one of the major arguments for generating quantiflers as a separate category in $N E$ does not hold for earlier stages; this is the necessity in NE of preventing the occurrence of more than one quantifier in the same noun phrase. ( I am overgeneralizing quite a bit here; only some quantifiers must be prevented from co-occurring in the same noun phrase: some few men, "all some men.) If it, does prove to be true that quantiflers can co-occur freely. In $\mathrm{OE}$ and $\mathrm{ME}$ and unt11 the re-analysis at the end of the sixteenth century, then the categorization of quantifiers as adjectives before that date is supported.

In $O E$, quantiflers could occur in a number of different positions, but not, apparently, in the most typical adjeca. tive position--between the determiner and the noun. This situation for quantifiers is not unique for adjectives, However, as possessive adjectives apparently did not occur in this position either; 9 it was argued earlier that possessives should be categorized as adjectives. Th1s means that the 
inability to occur between the determiner and the modifled noun did not make quantifiers distinct from (all) adjectives in $O E$.

In $M E$ and in the beginning of ENE, although it seems to happen only rarely, quantifiers do occur in this position to a greater extent than, in $\mathrm{NE}$ :

1297 in pe al worlde (OED: all)

a1300. our bather slogh (OED: both)

c1430 the bothe endes (OED: both)

a1500 Leeve you not this eich one (OED: each)

1589 Your some sweete smlles (OED: some)

1615 Your e1ther person (OED : either)

1615 Two rocks... whose each strength... (OED: each)

1704 The massie Goblets... Whose each capacious womb (OED: each)

Quantiflers are being treated like absolutely normal adjectives when they occur in this position. This list includes the latest examples that I have found of the construction (excluding examples like this much bread in NE), so it seems that the construction--though rare--was a possible one unt 11 the early seventeenth century. This lends some support to my proposal that quantifiers were re-analyzed and established as a category at about this time.

\section{Conclusion}

The distinctive syntactic features of quantifiers in $N E$ do not distinguish them in $O E$ from the category of adjectives. The variety of positions with respect to the modifled noun and the ability to be used freely as substantives are features shared by quantifiers and other adjectives 
In $O E$ and theréfore, I propose, a syntactic distinction in category membership between quantifiers and adjectives is not justified for $O E$.

Throughout the ME period changes in the usage of nouns, adverbs, and numeral, possessive and attributive adjectives resulted in the decrease of the syntactic features they shared with quantifiers; quantifiers began to look like a distinct class. They had acquired four exception features

is by the end of the sixteenth century, which proved to, be enough to provoke a re-analysis in which a syntactic category of 'quantiflers' was 'created.'

This re-analysis is seen as the effect of the Opacity Principle, a possible principle of the theory of grammar. The distinctness of quantifiers as a class at the end of the sixteenth century was due largely to the effects of changes that had occurred in other categories in the grammar, and particularly to the growing distinctness in the category of adjectives from the categories of nouns and adverbs; for this reason, the history of quantifiers. Is seen as a good example of support for the autonomy thesis. 


\section{FOOTNOTES TO CHAPTER 2}

1. For simplicity's sake I will refer to each, all, every, any, some, etc, as quantifiers throughout the paper, , although I propose that no such category exists in OE and $\mathrm{ME}$.

2. See, for example, Dougherty 1970 and 1971. These restrictions could also concelvably be semantic in that no reading--or a conflicting reading--is assigned and the sentence is thrown out if the co-occurrence restrictions are violated.

3. This analysis is not without problems, however. As stated earlier, after a possessive or.demonstrative (se or pes) an adjective occurs in the weak form. This distinction in weak versus strong form would be more difficult to state if possessives are analyzed as adjectives. I have no solution to this problem, but can only point out that the use of the weak and strong forms was somewhat confused even in OE (Quirk, p. 69; Campbell p. 261), so that perhaps a simple way to state the distinction is not as valuable as it may at first glance seem to bc. One might be tempted to propose that a semantic solution could perhaps be found in terms of the definlte versus indefinite distinction; these words are sometimes even used as labels in place of weak and strong. However, this would seem to result in syntac- 
t1c rules (rules of case marking and agreement) being subject to semantic factors, which is cohtrary to this study's approach to Iinguistics.

4. It might be that the use of a partitive in oE had more to do with the semantics of a word than with (mere) syntactic restrictions, as evidenced by the conspicuous absence from these construction types of all and both-quantifiers that do not have a genuine partitive sense.

5: Note the use of the strong form of the adjectives here.

6. Originally - lice was not itself an adverb ending; - Iic was a suffix used in deriving an adjective from a noun, and the -e is the same dative-instrumental case ending used to form adverbs from adjectives. But -e added to forms in - lic became so common that -1ice was as a whole interpreted as an adverbial ending and added to words that the -ilc form's meaning would not fit (Strang, p. 272).

7. Note that Jespersen here is talking about somewhat different usages than the ones Mustanoja ( $p .277$ ) calls French plurals on adjectives. However, when these French plurals occur with adjectives being used substantivaliy, they will make them look like nouns and so conlribute to the growing loss of substantival function for adjectives; whether the $-\underline{s}$ is a French or English -s makes no difference in this case because it can be interpreted as the growing English plural -s. 
8. The examples that do not fully conform to the pattern followed by all of the others are all with both (ex-. cept one unclear case with all):

al400 both her love (MED: bōthe')

c1430 by their both assente (OED: both) (Here the position conforms to the general pattern, but no inflection

c1400 bobe oure will (MED: bōthe)

al400 bothe our hoostis (MED: bōthe)

al500 bothe per thees (MED: bothe)

In four of these quotations the quantifier occurs first; however, this deviation from the pattern may perhaps be explalned by the fact that both bo and böthe occur at this time and bo seems to normally follow its noun-elther immediately or postposed to a position farther right in the sentence. So there may have been pressure to further differentiate these two forms by strengthenIng the positional difference between them. At any rate, there are many more examples with both that fit the generai pattern exactly, and only these few that do not. One more exception to the general pattern is: Chaucer I have herd al youre opinion $\gamma$

A here could be adverblal and refer to youre opinion

$\checkmark$ as a whole, so this may not be an exception.

9. Kellner (p. 138) does, however, cive three examples in which a possessive is preceded by se (Orosius: Se heora cyning and two in Blickling Homilies). Again, further study would be necessary to determine the point 
for certain, but it seems (from Mustanoja, p. 298) that predeterminer position for possessives was the common one. Also note that hora is one of the indclinable possessives (and the form hera is a genitive of the personal pronoun), so it could be interpreted as the genitive of a pronoun rather than as an adjecfive; this may be a fine line to draw. 


\section{CHAPTER 3}

\section{THE 'EACH OTHER' RECIPROCAL CONSTRUCTION}

Each other is sometimes described as having become: a
compound, sometimes as geing only the juxtaposition of each
and other. Morris $(p, 150)$ says that al hough each other
is sometimes called reciprocal pronoun it is not a compound; "... In such phrases as "love eăch other," "lave ong another," the construction is, each love the other; one love another; each and one being subjects, and other and another objects', of thelr respective predicates" (Morris, p. 150). Dougherty $(1970,1971,1974)$ also claims that each ather is not a pronoun or compound. The OED (each) says that each, and other "...have however long become a compound..." Visser (p. 445) agrees that each other "...began to be realized as a kind of compound object... If the change In status should have been coeval with that of 'each other! to 'at each other', and with the introduction of the genitive 'each other's', it could only have happened after the Middle English period..."

I w1il first present some different ways of expressing reciprocity that have occurred throughout the history of English; then describe the history 'of the 'each other' con'struction in more deta11. The diachronlc changes that have occurred in the 'each gther' construction wili be examined from the perspect1ve of two synchronlc analysals, for NE- 
"one proposing that each other is a pronoun in NE, the other arguing that' it' is not. The analysis of the history of the 'each other' construction.will be seen as providing evidence In the cholce between these two analyses. One of the anaIyses w1Il be seen to be able to explain the diachronic changes $1 . n$ " the 'each other' construction as an example of a re-analysis provoked by the Opacity principle. The proposed re-analysis occurs at the time of the historical changes which visser suggests were the Indlcators of the realization of each other as a compound object; an explanation for the "occurrence of the re-analysis at the time of these changes is offered.

Types of reciprocal constructions

English in earlier times had. quite a few ways of expressing the reciprocal notion. Below are examples of eleven types (based on Visser, pp. 439-447) including the first and last occurrences of them listed by Visser (p). 439-447) unless stated otherwise:

1) Simple pronour--not very frequent in $\mathrm{ME}$

Beowulf Naes...long to. Son, Saet pa aglaecean hy eft cemetton

c1400 But, syr meyr, May y take with the sofour? Som tyme we knowe us yore 
2) Personal pronoun plus adverb:' gemaenelice in OE; emel, samen, and together in ME and later

Defensoris Liber Scintillarum Gebiddap eow

1440 gemaenelice (translating: orate pro invicem)

Two marchauntes louyd hem to-gydere

3) Personal pronoun plus preposition--very frequent. In $O E$ and early ME

AElfred Ne untreowsige ge no eow betweoxn c1250 ofte sibbe men foken (=decelve) hem bi-twenen

4) Every other

cl175 We luuten ure efrec oder us b1-twenen swa we weren brodre

c1386 the lovynge children, that whilom loveden so flesshly everich oother, wolden everich of hem 'eten oother, if they myghte

1470-85 they...wounded everyche other dolefully

$$
\text { f }
$$

5) E1ther other

Trin. Coll. Hom. "besse wise beswikep her aiper ofer c1522 If we loue elther other

6) Other alone

al023. Ne bearh nu foroft zes1b zesibban,...ne bropor

1620 I would have caused you to slaye other

1809 We know not other--oceans are between (quotation 1 s from Campbel1)

V1sser states: "Th1s now obsolete usage occurred in later use only in Scottish dialects, where it is also found in other funct.lom: thin as object (p. 1/43):

1785 whon a youthlul, loving, molest pair, In othorres arms, breathe out the tender tale

Except for Scottish dialects, it seems that this use of other ceased at about the end of the sixteenth or beginning 
of the seventeenth century.

7) Personal, pronoun plus self

AElfred Alexandres aefterfylgendas...hu hie hie selfe mid misselilcan gefeohtum fordydon

1605 Get thee gone; tomorrow We'll hear ourselves again

Visser also lists:

1759-67 What can they be doing, brother?--quoth my father,--we can scarce hear ourselves talk

However, this seems to be a questionable example of reciprocity.

8) No object (expressed) plus adverb: samod/samen, betwuh, together, and mutually; very frequent with together in $\overline{M E}$ and In Shakespeare

cl225 He hehte alle his peines \& adele his cninte
fon somed to fihte

1655 Making her belleve that... as ofte as they shold medle together, if she were...confessed by him, she shold be cleere forgiven

1820 Scott The two brothers met as brothers who loved each other fondly, yet meet rarely together

$1847 \mathrm{Ch}$. Brontë We mutually embraced

1870 Tennyson For here two brothers one a king, had met And fought together

$1896 \mathrm{~A}$. E. Housman Towns and countries woo together

1908 Wells I put my arms about her and we kissed together.

9) 'Q...other' Another way of expressidg the reciprocal notion was with other--without a determiner--and a quantifier towards the beginning of the sentence to make the reciprocal notion more distinct (VIsser, p. 444). Many quantiflers seem to be able to occur in this use; or course, since other alone could express the reciprocal notion, it is limpossible to tell how much the quantifier contributed to the meaning.

a11... other

c1380 Alle dedes and werkes of pe Trintte mal not be departid from opir. (OED: other). 


\section{each.... other}

c893 \& swe aelc aefter oxrum (rOED: other)

c1522 the conflict of diuers qualified elementes in - our body, continualiy labouring ech to vanquish other

1538 Ych one to the profyt of dther (OED: each)

1611 Let each esteeme other better then themselues (Authorized Version of the Bible; 20th century version: each of you should humbly reckon the others to be of more account than himself; Jespersen II, Appendix 5.56)

either... other

Andreas AEgper para eorla odrum trymede Heofonrices

1677 There seems to be a more connatural Transmutation of either into other (OED: either)

every... other

1154 AEurlc man sone raeuede ofer pe minte (OED:

a1500(c1465) Every kynge werred upon oper MED: ever1)

none... other

c1400 Noon of hem neuer tofore had seye ober, ne noon of hem knewe opirs persone ne knewe of ofirs comyling (OED: other)

1422-1509 non of us may well helpe other

one... another

1548 Wone thèn labored another touerthrowe

1551 nature dothe provoke men one to healpe another

1597 It is certaine, that either wise bearing, or Ignorant Carriage is caught, as men take diseases, one of another (Jespersen VII, 17.7)

outher...other

c893 Nir heora ayer meht on ofrum size zeraecan (OED: outher)

al450 Nys man'1n erthe... Shall...pces make, Er outher of vs haue other slayne (OED: outher) 
any. . other

c1386 If eny [varlous readings any, ony] of us have more than other, Let him...part it with his brother (OED: any)

one... other

1604 tilting one at other's breast (Schmidt: other)

neither. . other

- c893 paet nader ne mehte on oprum size zeraecan *.

whether (=which of two)... other

al123 LOC, hweðer paera jebroðra oXerne ofer bide

both...other

al500 But yef they loue both othir, thay shall be in gret myssals (MED: bothe)

10) One another. Th1s expression of reciprocity 1s current in NE; first quotation from Visser:

1526 Owe no thinge to eny man; but to love one another

11) Each other. This is also current in NE; Visser gives as first instance:

AElfric his suna ferdon, and denode aelc ósrum

of these eleven ways of expressing the notion of reciprocity, (1) - (4) apparently died out before 1500, (5) died out in the early sixteenth century, and $(6)-(7)$ had died out by about 1600 except for the use of (6) in Scottish dialects.

Regarding type (8) V1sser comments: "The gap in the quotations given below between 1655 and $1820--1 \mathrm{f}$ not due to 
uncompleted research--1s remarkable" ( $p$. 442). He has many examples before 1655, and only those listed above after 1820. Perhaps the use in these later quotations represents a (new) Innovation and is unrelated to the older use, or perhaps the use in these later quotations is archaic or poetic; three of the five quotations after 1820 are either Scottish or from poetry. One could argue, therefore, that type (8) also died out by about 1600 (and perhaps was reborn around 1820). In this case there are three ways of expressing reciprocity that died out by about 1600 .

Type (9) is now obsolete (OED: other), or st111 occurs with each, but only archalcally or poetically (OED: each). Most of the examples $I$ have of the 'Q... other' construction are from the late sixteenth century or earlier, a few are from the early seventeenth century; the only ones later than this are:

1657 Priest and people interchangeably pray each 1667 Por other (V1sser, p. 445)
Milton Responsive each to others note (OED: each)

1677 There seems to be a more connatural Transmutation of either into other (OED: e1ther)

1821 Keats Each unconfines His bitter thoughts to other TOED: each)

1867 What was to be done, asked the enraged boys one of another (VIsser, p. 445)

of these, the 1667 quotation is from Milton, whose work is not necessarily an accurate example of the English of his time. Visser states in his Preface: 
"... It is with due circumspection that quotations have been adduced from works to whlch the following statement, made by Addison in praise of Milton in Spectator no. 285, 1s applicable: "Another way of raising the language... Is to make Use of the Idlom of other Tongues."

The 1821 quotation from Keats is likely to be an example of the OED's statement about the poetical use of each...other.

Th1s leaves only three Instances of the 'Q...other' type later than the early seventeenth century. It 'seems justiflable toksay that the 'Q...other' construction with other alone had all but died out by the end of the sixteenth or beginning of them seventeenth century.

In the midale of the sixteenth century, the 'Q...other'. type begins to occur with the other instead of with other alone; by 1600 this appears to be the normal construction:

al548 When bothe the armyes were approchyng to the other (OED: other)

1593 Beauties red and Vertues white, of eithers .colour was the other Queene (OED: either) c1600 each doth good turns unto the other

1865 Nelther knew the other (Visser, p. 445)

Types (10) and (11) with one another and each other are probably the most frequent ways of expressing reciprocity in NE. One another has occurred only since the s1xtoenth century, but each other 1 is recorded in al1 porlods of the history of English from OE to NE. Each and other can occur in several difrerent types of constructlons:

1) Adjacent, as in 'The boys hated each other' (henceforth referred to as each other or each other sentences) 
2) With a preposition preceding as in tThe women gave compliments to each other' (henceforth the 'to each other' type).

3) In earlier periods, with a preposition between each and other (henceforth the 'each to other' type), as in:

1615 How these two could be...members...participant each of other (OED: each)

4) With a genltive/possessive marking as in 'They hoped for each other's ruin' (henceforth each other's).

All four of these types w1ll be referred to as the 'each other' construction.

There are some 1mportant syntactic differences between the 'each other' construction in NE and in the earlier periods. These differences and their explanation will constitute the topic of the remainder of this chapter.

Each and other as adjectives in $O E$ and $M E$

As was argued in the preceding chapter, each, along with the other precursors of NE quantifiers is best analyzed as an adjective in $O E$ and $M E$ and unt 11 a re-analysis at the end of the sixteenth century. Its different syntact1c uses can be accounted for as the normal use of an adjective In substantlval functions or as the normal use of a form of the (neuter) adjective in adverbial function. Other can also be best analyzed as an adjective for the earlier perlods of English; some of the Important points of 1ts history are given below. 
Other originally served as the ordinal numerai for 'second.' It was not unt1l the beginning of the thirteenth century that secound came into the language from French. Both oper and secound fulfilled the function of the ordinal for a time; by the midale of the fourteenth century secound became dominant (Mosse, p. 66; Strang, p. 272). The OED has quotations for secound from 1200 on, and last quotation for other as the ordinal 'second. "as the following:

c1400 Costome ys pe oper kynde

Other had meanings besides that of 'second' from the earliest quotations in $O E$ according to the $O E D$ :

'the remalning' singular: c893 Hu Gallie wunnon on Romane, Pene on opre healfe (OED: other)

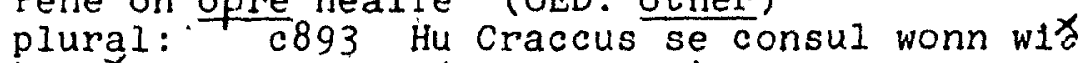
pa oare consulas (OED: other)

'existing besides, or distinct from, that already mentioned or Implied'

singular: c900 oxte on kysse bec oxye on oxre (OED: other)

plural: c888 Be paere sunnan \& eac be oxrum tunglum (OED: other)

All ordinals in $O E$ except other are declined like weak adjectives; other is always declined strong, even when occurring with a demonstrative or possessive pronoun (Strang, p. 302; K1spert, p. 118; Campbe11, p. 261):

c893 Se oxer consul zehierde Diulius (OED: other) c89 If Craccus se consul wonn wla ja oxre consulas al225 All so as on nell driue ut fen ơerne (OED: $C$ other)

In this way other differs both from ordinal numerals and from 
all other adjectives including quantifiers, which occur in the weak form when the syntactic conditions for 1 t are'met. As was normal for all adjectives, other could be used as a substantive, sometimes followed by a genitive plural or of plus a noun phrase:

Singular:

c893 pa jesette Galerius 11 cyningas under him;

c897 oper waes haten Seuerus (OED: other) (OED: other)

al425 pe broper toke pe operes wif (OED: other)

Plural:

971 Waes heora sum rexra... \%onne pa opre (OED: .

al100 On manezum Iandum $t 11 \%$ b1 redre Xonne on oxrum (OED: other)

Followed by a genttive plural or of plus a noun phrase as in the 'all of the boys' type:

c893 faer wear Leostenas, oxer heora ladteowa, mid anre flan ofscoten (OED: other)

13.. ooker [various readings auber, ouper, oon] 0 pam we most forga, For ma1 na man haf heuens Ewa (OED: other)

In NE, other cannot be used in the singular without a determiner or other qualifying word (e.g. any, some, no); this holds true for its use as an adjective or as a noun: D

* Other man drowned.

* Fred drowned, but other was saved. In $O E$ and $M E$ this restriction did not hold. Singülar other can occur wlthout a determiner or qualifytnp word when used adjectlvally or substantivally. This use for substantivized other is 1liustrated in the first, sixth, and seventh quotations above; the use of adjectival other without a determiner or qualifying word is 1llustrated by the first example, 
for c893 of other as meaning 'the remaining' and the second quotation (c888) for other as 'existing besides,...' In the plural, other has apparently always been able to occur without a determiner, as it does in the fifth quotation given above. But it is the abllity of other to, occur as a noun In the singular without a determiner that is of particular Importance in the analysis of the 'each other' construction. In the preceding section 1 t was stated that type (9) 'Q...other' began to occur with the other instead of other alone at about the middle of the sixteenth century, and that the last normal instances of other could be said to be at the end of the sixteenth century, or early in the seventeenth century. It seems that other began to lose 1 ts ability to occur without a determiner, at about the same time in other constructions as well; the latest quotations in the OED for other in a singular nominal function (other than in the 'Q...other' type) without a determiner are the following:

" a1694 Cor troversy, which I am less fond of every day than other

1480 The barons sent to hym o time and other 1

1596 Other than him they haue none ouer them

1483 All be he of his parente his affynyte or other

1561 Neuer thinketh vpon other but to please hir'

These quotations and those of the 'Q...other' type sugrost that other ceased to be able to occur in the singular without a determiner or other qualifying word by the beginning of the seventeenth century. The data given in the preceding 


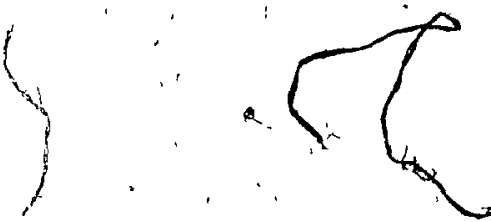

section on the use of plain other to express reciprocity agree with this date.

Other in 1ts substantival use took the normal strong adjectival plurą - $\underline{e}$ in $O E$ and in early ME. But when final unstressed -e is lost, other occurs in exactly the same form In the singular and in the plural instead of using the -5 . plural ending of nouns. (By 1200 -es is the ordinary plural markling for nouns according to Morris, p. 53.) Some examples of other as a plural are found In Chaucer; Malory has only other, never others; Caxton has other:

Chaucer other sayn (Jespersen II, 17.75)

c1477 Caxton The other deffended them with alle their puissance (OED: other)

1470-85. Malory But in no wise there was no knight about Sir Tristram that would believe that . nelther by his own hands nor by none other . consenting (Malory, p. 185; referenced by Jespersen II, 17.75 )

1545 Ascham This ignorauncie in men whyche know not for what tyme and to what thynge they be fit - causeth some to desire to be maysters and rule other which neuer yet began to rule themselfe (cufme, p. 174)

"Thl substantivized pl others begins to appear towards the middle of the 16th $\mathrm{c}^{\prime \prime}$ (Jespersen, II, 17.75). More usually has other but sometimes others, and the instances of gthers continue to increase until in Shakespeare others occurs as the plural far more orten than other. Later authors continue fo show both forms, but others is the more common one--except in Defoe (Jespersen II, 17.75):

1551. More the folysshehes of others (Jespersen 
1557 North That thy thoughtes were others than they seemed (OED: other)

c1600 Shakespeare as I all other in all worths surmount (Schmidt: other)

1611 Bible, Authorizgd Version To the others he said in mine hearing (OED: other)

The -s plural for ether is well-agtablished by Shakespeare's " time, or by about 1600.;

In $O E$ and $M E$, other is most simply treated as (only) an. adjective, with its substantival use treated as the homal use of an adjective in nominal 'functions. One could' also suppose, that other always existed both a's an adjective and. - as a noun, as in NE; the discussion that follows does not depend on treating other as an adjective alone. 3 The racts

- that other could occur without a determiner or qualifying word until about 1600 and that it occurred in the form other for both singular and plural from chaucer to' Shakespeare will be important in the analysis of the 'each other' construction."

The case system and each other

- Although each other has occurred in sentences from $O E$ to $N E$, with the more highly developed case systems of the earlier periods of English an-Interesting situation appears. In'NE each other can be, as a whole, analyzed ati the '(sur' face) object of a verbos in:

The candidates hated each other.

But this is not the case for $O E$ and early $M E$. 
The OED (each) states:

"Originally this" the reciprocal each other: was a phrase construed as' in 4 'Distributing a plural subject or object each being the subject, and other (inflected in OE. Ó drne, Oores, OS rum, etc.) being governed in acc., gentt., or dat. by a verb, prep.; or sb."

As long as the infilectional system made clear distinctions between the vartous cases of adjectives (some of which may -be used adverblally), each and other might occur adfacently but could not be analyzed as a unit because of their diferent inflections. All of the $O E$ and early ME examples I have found of the rectprocal each other show different inflections for each and other. (One apparent counterexample to this statement will be discussed later.);

The following are typical examples of each other with -other in the accusative (first two quotations), genitive, and dative:

1) al000 is is eallum pearf taet ure aejhwylc oterne bylde (OED: each)

2) O.E. Gosp. pa cruhtas beheolid aefe oferne (VIsser,

3) cl200 trat we sholden biwepen ure elch oxres sinne 4) Wulfstan Seowtan and Senian aeghwylc ofrum (Visser, In "EFe "Irst" quotation above, odare Is an acousative

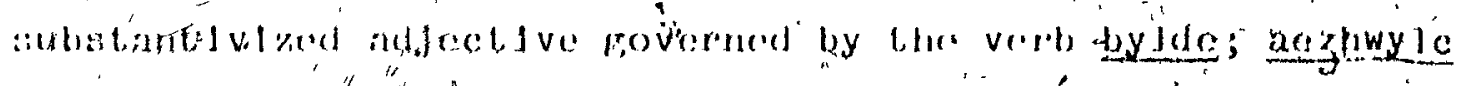
is in the nominative case since it 1 a a substantivized adjective used as subject of the clause $\frac{\text { ure aezhwylc olerne }}{\prime}$ bylde" (or, rather ure aezhwylc = 'each of us' is the subject). 
So although aezhwy Ic and oderne occur adjacently, it is clear that they perform the separate grammatical runctions of subject and object th the clause,

2) O.E. Gosp. Pá cnyhtas beheold aelc oferne (Visser, p. 446)

In the second quotation oSerne is an accusative case of the substantivized adjective functioning as the object of beheold. Aelc could be analyzed as, a nomfnative case, under. which interpretation the sentence has the two subjects d cnyhtas and aelc. This is apparently the only interpretation allowed by the OED's statement that each in the 'each other! construction in older English was the subject; Visser. (p. 445) suggests a two subject interpretation for sentences of this type and points out that the presence of two subjects was common earlier (e.g. "He Alexander cwaeb") " GMl occurs also in NE (e.g. "My rather he sald"). A second t. interpretation for aelc in this quotation 1 s that argued for In the preceding chapter for the type 'the boys were all...' Under this interpretation aelc is an accusative neuter form of the adjective used as an adverb. Under elther interpretatión, aelc and oferne are apain clearly

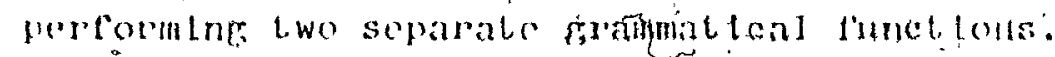
3) cl200 hal, wo sholden biwepen ure elch ofres sinne
(OLv: each)

In the third quotation both of these Interpretations are not possible. Elch cannot be analyzed as an adverb 
because of tife presence of ure (=lof us); the only possible Interpretation is that ure elch (='each of us') is a subject. If it is not possible to analyze elch as an adverb here, and if it is therefore necessary to analyze it as a second subject (w1th we as the other subject), then perhaps all. other instances of each, all and both in the, type, 'the boys were all...' should be analyzed as second subjects rathẹ. than as adverbs. The two subject analys1s accounts for all of these types, in a uniform way, whereas the analysis proposed in the preceding chapter cannot account for the third quotation abpve in the same way.

But there is another possible interpretation for ure elch which is not, inconsistent with the latter analysis. The precursors of NE modals (can, could, shall, should, w11l, would, may, m1ght, must; henceforth pre-modals) should be analyzed as main verbs' in $O E$ and $M E$ agcording to Lightfoot (1974). Lightfoot argues that, unt11 a re-analys1s occurred In the \$xteenth century in which the syntactic category of 'Dodal.' was created, the pre-modals exhibited tre behavior of normal verbs, Including the abtlity to take sentential complements. This means that, in this third quotation, we

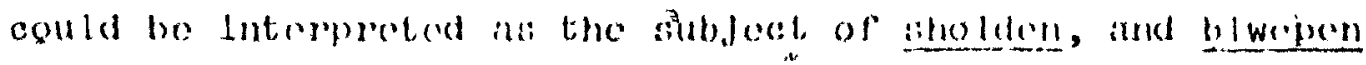
ure elch obles slnne could be a sentential complement to sholden. Under this interpretation ure elch is the subject of blwepen and ofres sinne is 1ts object. Elch is then the nominative case of the adjective used as a noun, and odres 
Is the genitive case of the substantivized adjective modifying

The noun sinne. This interpretation is consistent with the analysis of quantifiers proposed in the preceding ahapter, 'and makes 1t unnecessary to rely on the two subject analysis for any sentences. As in the other quotations, elch and odres are clearly performing separate grammatical functions and cannot be analyzed as a unit.

Unfortunately, there is a problem with this.interpretation of the quotation. Light foot (1974) states that the subject of the sertential complement to a pre-modal. "...was always deleted or moved out of subject position" (p. 27); the pre-modals shared this property with verbs like try. (e.g. 'She tried_to work hard). In the cl200' quotation the subject (ure elch) of the sentential complement to sholden has not been deleted; it has been moved out of subject position but not out of the sèntential complement altogather, which is what Light foot's examples suggest that he means. If so, perhaps Lightfoot's statement is too strong, and this is a counterexample to 1t. In any case, this $1 \mathrm{~s}$ the only example of this sort thdt I have, so 1 t could be at worst a single counterexample to the analysis: proposed in the preceding chapter for the type the boys were all...' It is not a gosslble countercexample to the claim that each and other in OE and carly ME show dif'erent inflections when they occur in each other sentences. This is also the only example before 1590 that I have 
found in which each immedlately precedes other's; however the c1200 example is to be interpreted, It does seem clear that elch oxres cannot be interpreted in the same way (1.e., as a unit) as each other's in a NE sentence like:

We hould forgive each other's sins.

In this NE sentence each other's is a (group) genitive mod1fying sins (1.e., equivalent to the sins of each other').

This interpietation is not possible for the ME quotation because both elch and otres woukd then be in the'genitive case; the modern English practice of puttins the genitive, .. or possessive, inflection on only the last word of a phrase-the group genitive--did not come into the language unt 1I the thirteenth century for an adjective/determiner plus noun (Jespersen VI, $17.1_{1}$ ), and even later for other types of noun phrases; for noun phrase plus prepositional phrase, Mustanoja (p. 79) says that the first instances of the group genitive are in Chaucer.",Also, if one tries to interpret elch odres in the ME quotation in the same manner as each other's in the NE sentence above, one is left with no slot in the sentence for the genitive ure. More will be sald later about. the genitive/possessive of each other In the next section.

11) Wulfatan Scowlan and Senian acriwyle ofrum! (Visser, p. 444)

In the fourth example I1sted above aeghwylc is the nominative caso of the adjective used substantivaliy as the 
subject of Seowian and Sentan, and odrum is the dative ob-. ject. Once again, as the inflections on aeghwylc and ofrum show, the quotation cannot be interpreted as an example of each other functioning as a unit.

In these four examples, then, and in all the other $O E$ and early have found In VIsser, the OED, or elsewhere, it is not possible to analyze each other as a unit; the inflections on" the words show that the two words perform two different grammatical functions.

There is an apparent exception to thls statement in eariy ME:

1100 On minan lande \& on "aelces ofres, mannes lande (MED: ech)

In this quotation aelces, ofres, and mannes each show the genfitive inflection. But this is not an example of the reciprocal each other; it is difficult to see how the sentence could even be Interpreted with aelces odres taken as expressing a reciprocal notion.

othex used to be the ordinal numeral meaning 'second' and 1 t appears that this meaning continued on in the $\mathrm{ME}$ and NE phrase every other; this phrase means 'every second' or 'every alternate' according to the olid (other). Inder

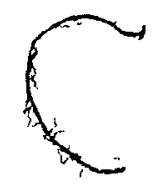
this meaning the OED gives the following quotations, amone others:

1480 For which raunsoune to be payed eche other chalyce of englond was molte and made in to - moneye (OED: other).

$$
86 \text { - }
$$


1588 Spending euery other day in such sporte (OED: other)

It appears that either each or every could be used in this phrase. Morris (p. 148) states: "Each other sometimes = each alternate, every other, as--"Each other word I was a knave."-Gammer Gurton's Needle" (15\%5). This is not surprising, since every and each used to be more or less interchangeable, with every being somewhat more emphatic, and there is st11l sometimes no distinction made between them (Jespersen II, 7.811). In fact, every (ME everl(ch)) was originally a compound from OE aefre and aelch (Jespersen VII, $\left.17 \cdot 5_{1}\right)$.

The OED gives no earlier examples than 1480 of every/ each other as meaning 'every second,' but since secound did not even appear in English unt1l the beginning of the thirteenth century, other must have been readlly interpretable as 'second' In 1100. It seems reasonable to suppose, therefore that aelces odres in the 1100 quotation $1 \mathrm{~s}$ an earlier example of the 'meaning 'every second' and is not an example of the reciprocal each other which 1s the concern of this chapter.

Another"1nteresting sentence 1s:

a1450-a1500(1436) Spayne and linaunters la an yehe

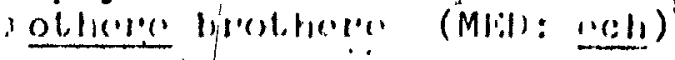

llere' it seem: yehe othere must have a reclprocal notion and both yche and othere have the same ending which may be the weak and/or plural adjectival endinr. it this late date 87 
the -e on yche would not still be interpretable as the adverbial ending -é; yche could be interpreted as an unchanged adverb, but the position in the sentence is an unusual one for an adverb. Since this is the only example I have of this type, it may be a hapax legomenon, or, since It occurs at so late a date, it may be considéred as a for'erunner of the $\mathrm{NE}$ each other's.

These are the only two examples in OE and early ME In which each and other show the same inflection and could possibly be functioning as a unit. In $O E$ I have no such examples, so for this operlod at least can state that each and other, though they may be found adjacent to each other, function as separate elements with separate grammatical functions as 1ndicated by the1r case endings.

It should be mentioned that there do not seem to be any examples in $O E$ or ME of each(...) other in which other is unambiguously plural. (In the dative the singular and plural of other are identical in form.) If the two words operate Independently of each other there is notreason that I can think of for the absence of this type, unless it has to do with other being st1ll feit as equal to 'the second' In which case the plural would perhatps be less natural.

\section{Bach other's}

There is only one example of which I am aware in which each occurs in a sentence immediately preceding other's 
before 1590--the early ME sentence discussed in the preceding section (cl200 pat we sholden blwepen ure elch odres sinne). In this quotation it is clear that elch is a nominative case subject and does not belong with the genitive Orres.

At the end of the sixteenth century a (group) genitive of each other first appears; when referring to each other's I mean a phrase that can be taken as the genitive form of the unit each other. V1sser, dates the flrst appearance of each other's as 1590, but he groups together each other's and one another's and his early examples (before 1816) are with one another's:

$\$$

1590 They strained one another's hand (Visser, p. 446)

1599 Why the devil should we keep knives to cut one

1816 That we may see each other's faces (V1sser, p. 446) Schmidt references ten examples of each other's in Shakespeare, among them:

1590 we still did meet each other's man ('Schmidt: each).

1593 You never shall, so help you truth and god, Embrace each other's love in banishment; Nor never look upon each other's face (Schmidt: each)

1599 , that the contending kingdoms of France and England, whose very shores look pale With envy of each other's happiness

1607 May cease the ir hatred; (Schmidt: each) make each to prescribe:to other as each other's leech (Schmidt: other)

'The types 'each to other' and 'to each other'

In $O E$ and $M E$ each other does not seem to have occurred following prepositions. There are only examples, with the 
preposition occurrytig between each and other:

o.E. Gosp, [HI] cwaedon aelc to osrum (Visser? p. 445)

c1386 They roynen ech at other (Visser, p. 445)

$1607^{\prime}$ Pages blush'd at him and men of heart Look'd wondering each at sther (Visser, p. 445)

$1657^{\circ}$ Priest and people lnterchangeably pray each for other (V1sser, p. 445)

This is the last example of the 'each to other' type given by Visser;" he notes: "According to the OED 'each to other" st11l occurs arch. or poet." (p. 445).

"So It seems that the type 'each to other' occurs from OE through ME and dies out--in normal use--by the middle of the seventeenth century.

The normal NE construction--the 'to each other' type-begins to occur at the end of the sixteenth century; Schmidt references two examples in Shakespeare:

1590 And lead these testy rivals so astray As one come not within another's way Like to Lysander sometime frame thy tongue, Then stir Demetrius up with.bitter wrong; And sometime rail thou 11 ke Demetrius, And from each other look thou lead them thus T11 o'er their brows death-counterfelting sleep With leaden legs and batty wings doth creep. (Schmidt: each; A Midsummer N1ght's Dream III, 11, 358-365)

1591 this shouldering of each other in the court (Schmidt: each)

Visser lists as first examples of this type:

1657 The llorses...struck at one another (VIsser, p. 446 )

1709 These Two Lovers seem'd...made for each other (V1sugr, P. 446) 
The explanation of the historical changes in the 'each other' construction

The following historlcal changes in the 'each other' construction have been described in the preceding sections: 1) Three types of reciprocal constructions died out at the beginning of the seventeenth century: type (6) Other alone, (7) Persqnal pronoun plus self, and (8) No object (expressed) plus adverb.

2) Each other's" is first recorded at the end of the sixteenth *entury.

3) The last normal (1.e., not poetic or likely to be archa1c) examples of the. 'each to other' type are in the first half of the seventeenth century; the first examples of the 'to each other' type are at the end of the sixteenth century.

These changes all took place at about the same time, so, in keeping with the approach to historlcal lingulstics described in the first chapter of this paper, one would look for one explanation that will account for all of the changes. One would also hope to find that such an explanation w1ll be in terms of general principles of historical change; the explanation to be preferrod is one that makes use of principles that are useful in the description or other diachronie changes. The determination of such prin- . ciples contributes to the development of a theory of change. There are two compet1ng analyses of the 'each other' 
construction in NE and two corresponding explanations of the historical changes presented in this chapter. One synchronic analysis for $\mathrm{NE}$ involves a semantic rule of interpretation for each other, while the other proposes a syntactic movement rule for each.

Dougherty (1970, 1971, and 1974) proposes an analysis of each other that involves a syntactic movement rule (henceforth each-Movement) to convert the first sentence below into the second:

(1) ?The men will speak each to the other.

2) The men w1ll speak to each other.

Both of these sentences ultimately derive from: 5

3). Each of the men will speak to the other.

The relevart stages of the derivation are that a transformation called Quantifler Postposing applies to (3) and ylelds:

4) The men each w111 speak to the other. The application to (4) of a second transformation called Quantifier Movement gives:

5) The men will each speak to the other. or, Dougherty claims: 6

6) ?The men w1ll speak each to the other Under the each-Movement analysis the base component will cenerate deep structures with the order of elements as in (3), but not as in (1), $(2),(4)$, or (5)--all of whigh are related to (3) by some combination of the transformations 
Quantifier Postposing, Quantifier Movement, and each-Movement. Each other is never present in deep'structure, but: is always the result of the application of these three Eransformations.

Jackendoff (1972) and Flengo and Lasnik (1973) 7 propose a semantic analysis of each other sentences. The essentials of a semantic analysis are that each other is freely generated in deep structúre as a pronoun under noun nodes 'and that there is a semantic rule' that assigns an. antecedent to each other and a semantic interpretation to the sentence in which.1t occurs. Jackendoff points out that "...thè environments of each other seem to be virtually Identical to those of refiexives, and any analysis which doés not capture this fact 's mising an important general1zation" (p. 173). He proposes that one rule can determine the antecedents of both refilexive pronouns and the reciprocal pronoun each other in an each-Interpretation analysis. This generalization would iresult in a more economical grammar than if "the two types. of pronouns had their antecedents determined.by two separate rules.

I assume a grammar, Invollving the trace theory of movement rules as proposed in Chomsky (1973) and developed in Chomsky:(1975, 1976). In this grammar ail semant1c interpretation is to bo done orf a surrace structure enriched with traces. A trace is left by a noun phrase in the position from which it moves in accondance with a syntactic 
rule. In a grammar of this type it seems that the eachMovement analysis will be more complicated in one respect than the each-Interpretation analysis.

In orderito determine a semantic interpretation for a sentence with each other in it" '1t is necessary to first. determine the (poss1ble) antecedent (s) of each other; the - antecedent w1ll determine part of the meaning of the sentence, - In the each-Movement analysis, the possible antecedents of each other w111 be those nouno phrases from which each" could have been moved by; the application of eachr. Movement in accordande with the conditions to which this rule" is subject (see Chomsky 1973). When each is moved by. the each-Movement transformation, it does not leave a trace since it is not a noun phrase. This means that when it comes time to do the semantic interpretation of a sentence. with each other in 1t, there will be no indication of the positiod from which each was moved and hence no indication of the antecedent of each other. So tt is necessary, in the each-Movement anaiysis, to have a semanta rule to determine the (possiblé) antecedent(s) of each other. "This rule is neded in addition to the syntactic each-Movement rule; -

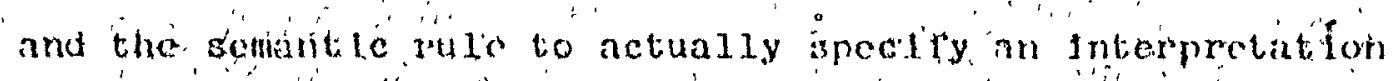
for the whole sentience.

-3o; both the each-Movement and the gaoli-Interpótétion analysis, need a semantic rule to assign a semantic interpretation(s) to each other sentences the former needs a rule "9.4". 
of each-Movement and a rule to assign an antecedent to each other, while the latter needs only a rule to assign each other an antecedent. The each-Movement analysis is more complicated to this extent; unless it is simpler or more adequate in other ways (e.g. In the statement of co- . occurrence restrictions on quantiflers and certain advepbs; see Dougherty $1970 ; 1971)$, the each-Interpretation is to be preferred.

This is one way in which to compare two synchronic analyses. In the case of the comparison of the each-Movement and each-Interpretation analyses, the assumption that (all) semantic interpretation is to be done off surface styructure makes it difficult to find empirical predictions that differ between the two analyses and on the basis of which they can be compared. 8 Historical data on the 'each other' construction provide an additional means of comparing the two analyses.

The each-Interpretation analysis of the diachronic changes In the 'each other' construction

For $\mathrm{OE}$ and $\mathrm{ME}$, sentences containing the 'each 'other! construction with no subject expressed (othor than each) are analyzed in the same way under elthơr the each-interpretation or each-Movement analysis of the ${ }^{\circ}$ diachronic changes consldered here. Examples of this type of 'sentence are:

1590 With greedy force each other doth assa11 (Visser, p: 444) 
1483 Thenne eche kyssed other and effbraced s.traytelye (Visser, p. 444)

Whether each precedes or follows the verb in "this type, it Is analyzed as a substantivized adjective used as subject and other is the object of the verb (or preposition, or is used as a genitive modifier of a noun phrasej. This type of 'each other' construction does not provide crucial evi-

- dence in dectalng between the two explanations offered; it is in the analysis of other types of 'each other' constructions that the explanations differ.

Under the each-Interpretation arpalysis of the diachronic changes in the 'each other' construction, the general explanation is that in $O E$ and $M E$ each other sentences and the 'each to other' type are analyzed with each as an adverb. and other as the object of a verb or preposition or used as a genitive modifier of a noun phrase. This interpreta- . tion becomes opaque towards the end of the sixteenth century, and a re-analysis of each other takes place such that it begins to be anklyzed as a pronoun. A rule of each-Interpretation enters the language at this time to provide an antecedent for this pronoun--or perhaps the reflexive antecedent rule is generalized to determine antecedents for each other as well as for reflexive pronouns (if such a rule exists at this time; I will not' go into this aspect further). There is in $O E$ no pronoun each other and no rule of each-Interpretation. I propose that each other and the 
'each to' other' type sentences are analyzed in $O E$ with each as an adverb; this adverblal use of the accusative nẹter form of an adjective was discussed in the preceding chapter. Other in $O E$ is the adjective used as the substantivized object of a verb or preposition, or as a genitive modifier of a houn. This is possible because other alone (1.e. without a determiner or other, qualifyirg word) can occur in substantivized functions in $O E$. This interpretation becomes opaque later for the following reasons.

First, the simplification of the $O E$ inflectional systeh makes it less clear that each and 6ther perform different grammatical functions in the sentence. Each begins to occur without a clearly nominative case ending or a clearly adverbial ending: *

1398 Foules that lyue by blode ete not eche other $1485^{\circ}$ (OED : each) 1573-80 They do hate ech other deadly' (visser, p. 446) In sentences with no other subject than each, it is clearer that each and other have separate grammatical functions, for no subject can be found if each other is interpreted as a unit:

$125 \% 8$ faet aehc oper helpe faet for to done, (OED': each) . But in sentences $11 \mathrm{ke}$ those in the rirst, rroup qudted, above, each and other could be interpected as a unil; therests in. longer any morphologleal marking to prevent weh an interpretation. . 
Second, other begins to lotse its ability to occur without a determiner or other qualifying word. Once other begins to require a determiner, as in $\mathrm{NE}$, the $\mathrm{OE}$ analysis proposed here for each other is no longer possible. Other seems to begin to require a determiner in the second half of the"sixteenth century; in the reciprocal type (9) 'Q... other' the other begins to occur instead of other alone at this time, and by about 1600 the other seems to be the normal construction, although (normal) instances of other alone still occur, in the early seventeenth century. During this time, a f'ew instances occur in which each and the other are adjacent:

1586 while each the other did deprave (V1sser, p. 445)

1590-6 Striving each th'other to undermine (Visser, p. 445)

1590-7 Each the other from to rise restraine (Visser, . p. 445)

1647 Justled each the other too much (OED: each)

Thṭd, other begins to take the normal -s plural marker. for nouns, so other in the 'each' other' construction is no longer interpretable as a plural. It is interesting to note that Scottish dialects formerly used each others to refer to more, than two persons:

al649 'They mutually entertained and feasted each others at Christmas (Visser, p. 448)

Fourth, the Interpretation of each as an adverb becomes opaque in thè sixteenth century. I have discussed one aspect of this argument in the preceding chapter regarding quantiflers in general; the language's campaign against 
unchanged adverbs seems to be quite strong in the middle of the sixteenth century. This means that the form each is then becoming opaque as an adverb; the tendency is to have adverbs end in $-1 y$ and so to be distinct from adjectives: But the position of each in each other sentences is also becoming opaque for an adverb at this time.

The position of each in the following sentences is post-verbal:

c1386 They foynen ech at other (V́1sser, p. 445)

cl340 hy louyel ech of ren ase ham selue. (Visser,
p. 446 )

The position in the second quotation is no longer a possi- ble one for adverbs in NE; ech occurs between the verb louyef and the object of ren, in what. I will refer to as post-verbal "position. Adverbs do not normaliy occur following the verb in NE except when at the end of the sentence (Jackendoff, p. 68)--unless the adverb precedes only other adverbs or: prepositional phrases. The only sentences in which an adverb" can occur between the verb and object in $\mathrm{NE}$ are those with a 'heavy'9 object (e.g. The giraffe selects carefully the youngest and tenderest leaves upon the tree that are within its reach.)

This restriction on adverb position does not seem to have aliways existed. Nlthough I have been unable to.rind a statement in a grammar about this position, a cursory search through the ${ }^{5}$ OED and MED has given me a number of examples in which the, adverb occurs post-verbally and in<smiles>[LiH]</smiles> 
which the object is not 'heavy:'

c1000 Abraham ta undernam héfiglice las word (OED: heavily)

c1000 Fadward king gret wel Willem biscop (OED: . wel1)

al122 Ic Agathe...grete wel seo wurofulle AEdelred (OED: wel1)

c1250 Jaban and his moder... fagneden wel is sondere man (OED: well)

c1330 Sorlandes...o:ain ferd For to taken quicklike e children ('OED: quickly)

c1400 And tat ye recorde wel e cumantemens of god (OED: we 11)

c1400 Seyntes gyfen accydentaly blisse, when pei be objectis to glade oler seyntes; bot God hymself - deles, as he acceptis seyntes (MED: accidentalli) c1450(c1405) Hit is pe holsemyst pyne...To bringe boldely a-bedde e best of e royaulme and arise.

c1449 We desyre...l at ye wolli... shew gracyeuxly your special favour \& benevolence to us (MED: grac1ousiy)

1483 Bere esily thy harme \& it shall greue the the lesse (OED: eas1ly).

al529 Note and marke wyl thys parcele (OED: well)

1566 speake hardly thy minde (OED: hardly)

A much more comprehensive study would be required to allow a strong statement about the time at which this position. ceiased to be avallable to adverbs, but it does seem from the ease with which these examples were found that postveribal position was productive for adverbs at one time. Since no example later than 1566 was found, I will state tentatively that post-verbal position ceased to be a productive one for adverbs sometime in the sixteenth century.. The position of the negative not during the sixteenth and seventeenth centuries, is consistent with this statement. Not used to' occur normally after. the first verb, whether that was a main verb or a pre-modal, giving patterns like

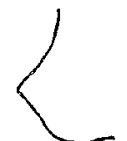


'I w11l not say' and 'I say not.' In the early sixteenth century not began to occur before the main verb; the pattern was either 'I do not say' or 'I not say.' AII' of these patterns co-existed for some time; it was not until the late seventeenth century that nat became muçh less common in postverpal position ( Lightfoot $1974, \mathrm{pp}$. .28-9). It may be that the type 'I spoke not' occurred later mostly when there was no. (direct) object of the verb, so that this pution was not then the same as what I have called post-verbal position for adverbs; more study would be needed to decidathis point. But my purpose in referring to the positions of not Is merely to establish that there was a tendency in the sixteenth century to avoid post-veppal position in favor of pre-verbal. This tendency may have operated simultaneously on adverbs and on the negative not. This change in the negative construction lends plausibility to the statement that post-verbal position ceased to be productive for adverbs sometime in the sixteenth century.

$\dot{I}$ propose that the fact that adverb's ceased to be a'ble tó occupy a post-verbal position as well as the language's campaign'against. unchanged adverbs in favok of the -ly type made the analysis of each a's an adverb in the 'each other' construction opaque by the midale or end of the sixteenth century.

Fifth, the growing regularization "of word order has an effect on the opacity of the analysis proposed ror each 
-other In $O E$ and $M E$. Jespersen $\left(V I I ;, 2 . I_{8}\right)$ gives the roIlowing percentages (among others) of svo order for the sentences that contain a subject, verb and object:

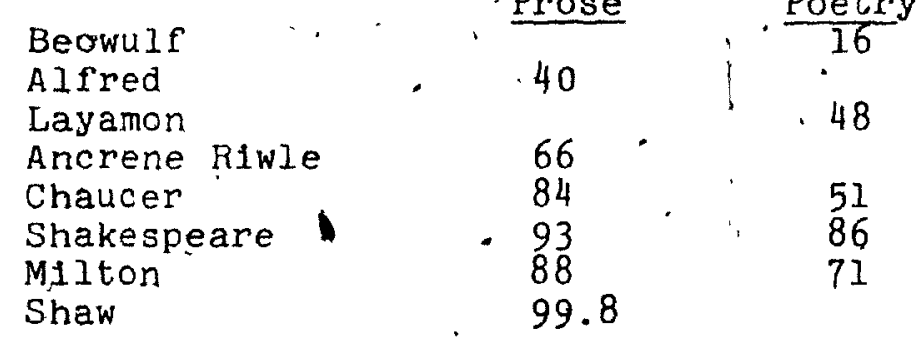

It can be seen that there has"been a steady Increase in SVO order, which reached a peak at Shakespeare's time. By the. end of the sixteenth century there would have been a strong. tendency to analyze a given sentence as exhibiting this nearly general word order.

"The increasing regularity in svo order means that the number of each other sentences with no other subject expressed is probably decreasing; the analysis of these sentences with each as subject is certainly beching opaque as the regulartty of the order SVO Increases, since in these sentences the subject each occuns after the verb:

Wulfstan deowian and denian aeghwylc offrum (Visser, p. 444)

The increase in svo order also has an effect on each. other sentances in which a subject is expressed, e.g.: I485 We will helpe eche other (VIsser, p. 446) \& In these sentences there is a subject, then a verb; and then each other. The tendency to analyze sentences as 
- showing the increasingly general svo order could result in this type of semtence beginning to be analyzed with each. other (as a unit) as the object. Since ach is becoming opaque as an ddvefb' and'eche other is' in the most 'favored position for objects,. I propose that the pressure imposed by the growirig regularity "of svo order' contributed towards the re-analysis of each other as a pronoun so that it could, as a unit, occur as the object of the verb. Each child has to develop his own grammar of the language he is learning; if the number of each other.'sentences' with no' (other) expressed subject (e.g. he quotation from Wulfstan above) was rather small because of the increase in svo order, the chlld has mainly the latter type (e.g. the quotation from. 1485 above) from which to draw hils analysis of each other. Belng influenced by the' large majorlty of sentences with svo order, he tries to impose this order on as many sentences as he can. In the case of the second type of each other sentence the Imposition of svo order works if each - other as a unit is analyzed as the object.

For these five reasons; the analysis of the 'each other' construction for $O E$ and. $M E$ is becoming opaque in the sixteenth century, and a re-analysis 'was provoked at the end of the. sfixteenth century: each other was re-analyzed as a pronoun. Th1s proposal offers an explanation for the changes in the 'each otheri contruction described earlier. First, the loss of three types of reciprocal construc- 
tions occurs in the eardy seventeenth century--just after the proposed re-analysis of each other as a pronoun. Earlier In the sixteenth century one another had been introduced, into the language as a reciprocal. The later establishment of each other as a réciprocal wolld make' it unnecessary tro have, so many other ways of expressing reciprocity, so some could easily be. lost as 'reduindant.'

- Second, the fact that each other's is first recorded at the end of the sixteenth century is explained if such a re-analysis of each.other is assumed to have taken place. Undeir the analysis of each other proposed in this chapter for $O E$ and $M E$, there is no reason for there not. to be some instances in these earlier periods of each immediately preceding other's, as in the early ME quotation discussed earlier (c1200, pat we sholden bliwepen ure elch ores sinne).: However; in order for such instances not to be counterexamples to the analysis I propose, each and other's "In such instances must not be analyzabie as a unit. Thus, as in the cl200 quotation, it must be clear that each is a nominative subject (or adverb) and does not belong with the genitive other's.

However, one would not expect to find each other's in OE or ME w1thin a prepositional phrase as in the 1593 and 1599 quotations from Schinidt:

1593 You never shall, so help you truth and god, Embrace each other's love in banishment; Nor never look upon each other's. face (Schmidt: each) 
1599. that the contending kingdoms

of France and England, whose very shores look pale With envy of each other's happiness

May cease their hatred (Schmidt: each)

The adverb (or substantivized adjective used as subject) would not be expected to occur in that position; nor would this each be expected to occur within an as-phrase as in the following quotation: . . .

1607 -make each to prescribe to other" as each other's leech (Schmidt.: other)

So the analysis of the 'each other' construction which I propose for $\mathrm{OE}$ and $\mathrm{ME}$ correctly predicts that quotations like these could not. occur in $O E$ and $M E:$ But once each other is re-analyzed as a pronoun, it 1 s free to occur in all the positions available to nouns (provided that there is an el1gible antecedent for $1 t)$.

Third, the fact that the type 'to each other' begins to occur at the end of the sixteenth century is explained by the re-analysis of each other as a (reciprocal) pronoun. If each other is a pronoun it can be generated in any noun slot-for instance, after a preposition. 10 The 'each to.. other' type dies out because adverbs can no longer occur following a verb, bther begins to require a determiner, (ajd' perhaps also vecause it begins to look like a split compound. Another bit of historical data also seems rebsonable In view of the proposals put forth here, and thus offers. some support for them. Visser (p. 447) 'states: "..there was formerly occasionally a tendency to provide the verb 
with an accumulation of reciprocal objects and adverbs";

he gives qxamples from Ben. Rule to 1682 , including the

* following (from p. 447):

Ben. Rule la opre heom gemaenelice betwuh on pisse.

c1175 We luuien ure efrecoter us bi-twenen swa we

cl175 We luuien ure efrec oier us bi-twenen swa we

c1375 fan kissit ai ilk o er sammyne (OED inserts

1380 that thei sle to gidre hem silf (1534. Tyndale:

1613 his mind and place Infecting one another...

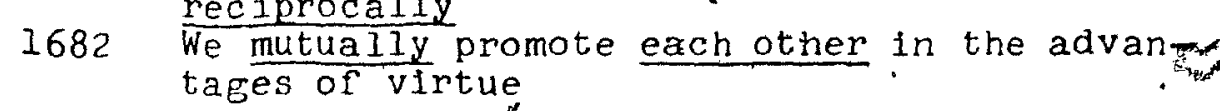

Like the loss of'three ways of expressing reciprocals soion

after each other was re-analyzed as a reciprocąl pronoun, these data seem reasonable in 11 ght of the re-analysis proposed.' once there were two main ways (each other and one another) of unambiguously expressing reciprocity, an accumulation of reciprocals in one sentence, like the accumulation - In the language of many different ways of expressing reciprocity, becomes unrecessary.

So, the historical data presented here can be adequate- . ly explained with the proposal that the $O E$ and $M E$ analysis of each other sentences became opaque by the end of the six-" teenth century and a refanalysis was provoked in which each other began to be analyzed as à (rectprocal) pronoun: 'At this time a rule of each-Interpretation came into the lan'guage to determine an antecedent for the new pronoun. "The explanation is in terms of the same general principle that 
was used in the analysis of quantifiers in the preceding, : . chapter--the Opacity Principle.

The each-Movement anajysis of the diachronic changes ind the

1 'each other'. construction

Until the end lof the sixteenth century, the analysis of the 'edach other' construction is the same as' that des-. . cribed in the previous section. Each'1s analyzed as an adverb and other as an object in each other sentences, and in thie "each to other' type." There'is no rule of eachMovement in $O E$ and ME. To propose that there was such a rule for these periods would miss generalizations; since. each had the distribution of both adjectives, and '(at least some) adverbs, it is most ećnomically treated as an adjective which can, like all other adjectives, be used adverblally in some of 1t's cases. If each is treated as àn adverb its position in each other senetnces and is the 'each to other' type is pcounted for as the presence of an.adverbin post-verbal position, and no rule of each-Movement is needed.

When adverbs can no longer occur post-verbally, and each is opaque as arjerb form because of the increased. use of the -ly form, the each-Movement rule is introduced Into the language to ppoduce the same output as in of and ME--the each'othert sentuges".

But there are two problems here. First, $1 \vec{t}$ logk $\$$ thoug the loss of post-verbal position for adverbs and the 107 


\section{6}

Introduction of each other's and the 'to each other' type, occur simultaneously; -this means, that when the eachMovement ale is first introduced it does not produce the same output as, in $O E$ and $\bar{M} E$, but produces in addition each other's and the 'to each other' type, neither of which existed before. Second, there is no reason given for the maintenance of post-verbal position for each when it is lost for all (other) adverbs. The each-Movement analysis. for NE does not seem to allow a principled explanation for the introduction of the each-Movement rule or for the introduction of each other's and the 'to each other' type.

However, as has already been stated, the data on postverbal position do not allow a strong statement to be made about the date at which this position was lost to adverbs. If the accumulation of more data were to show that the loss of post-verbal position for adverbs occurred at an earlier time than the first occurrences of each other's and the 'to each other.' type, a more reásonable explanation 'cán be' offered for the dlachronic changes. There would then be two stages involved in the change--the first in which adverbe lose the ability to occur post-verbaliy, the second in which each other's and the 'to'cach other' "type are introduced.

The each-Movement rule at the eairlier stage would look like this:

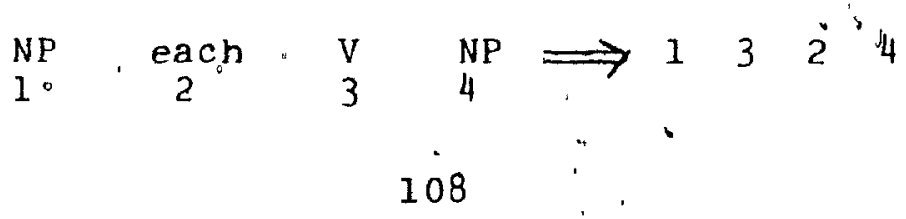




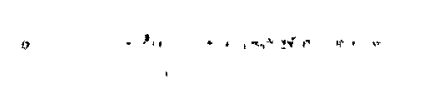

For the later stage, in, which each other's and the 'to each other' type have begun to occur, the rule would look like this:

$$
\begin{array}{llll}
N P & \text { each } & X & N P \\
1 & 2 & 3 & 4
\end{array} \Rightarrow \begin{array}{llll}
1 & 3 & 2 & 4
\end{array}
$$

The each-Movement rule for the earlier stage allows each to move only to immediately post-verbal position--its position In each other. sentences or in the 'each to other' type.. For the later stage the structural description of the each- . Movement rule has been generalized to allow each to move over an unspecifled amount of material to a position Immediately preceding an NP; it can move over a verb and a' preposition to yield the 'to each other' type, or over a number of words to produce each other's in a position in which it could not occlir during any earlier period (e.g.

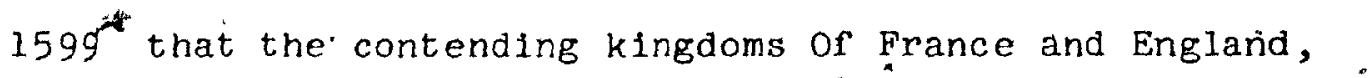
whose very shores look pale With envy of each other's happiness May cease their hatred; Schmidt: éach). Under this assumption about the date at which post-verbal position for adverbs was lost, the each-Movement rule is introduced in order to produce the same output as in OE and ME. At the later staje the rule is generalized; the generalization of a rule certainly seems to be a possible type of historical change. The question of why post-verbal position for each was maintained while it was lost for all othen adverbs still remains unanswered. In addition, no explana- 
tion is offered for the loss of three other ways of expressing reciprocity shortiy after these changes in the 'eachlother' construction take place.

If the loss of post-verbal position for adverbs" can be shown to occur at an earlier time than the introduction of each other's and the 'to each other' type, then the each-. Movement analysis of the diachronic changes rests on a tendency, or desire, to preserve the output of an earlier period. But a tendency to preserve an earlier output can surely not be a general principle of diachronic change--it is contradicted y every historlcal change that takes place. Such a principle would not be expected to be developed as part of a.theory of language change; it. would merely predict that sometimes (possible) changes would not take place.l And if the 'loss of post-verbal position for adverbs did occur' at the same time as the introduction of each other's and the 'to each other' type, the each-Movement explanation faces another problem in explaining these changes. Not only is. post-verbal position for each preserved while it is lost for other adverbs, but also not even the proposal of a 'tendency to preserve the same output:! as a principle will

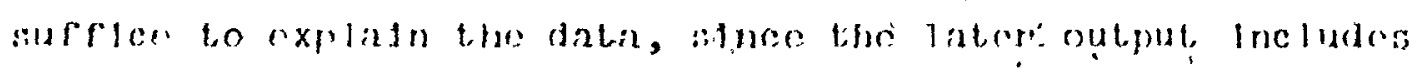

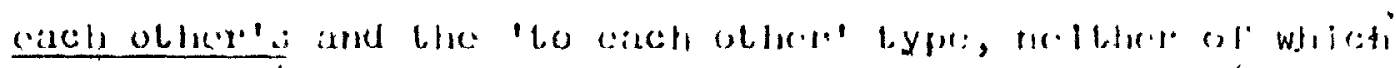
occurred earlicr." 


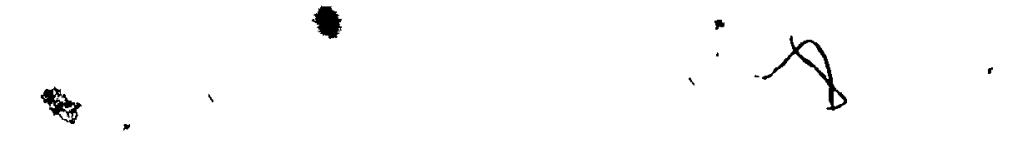

Conclusion

The each-Interpretation analysis for NE allows. a principled explanation to be made for the dlachronic changes in the 'each other' construction that are described here?: The explanation is based on a general princsple--the opacity Principle. The presentation of support for this principle contributes to the development of a restrictive theory of grammar.

The each-Movement analysis for NE also allows an explanation of the diachronic changes, but it is not clear, " that it allows any principled explanation to be made. The explanation offered here does not seem to support any principles of grammar or principles of change that may aid in. the development of a theory of grammar or a theory of lan-. guage change.

The adoption of the each-Interpretation analysis for NE provides a good explanation of the changes in the 'each other' construction, whlle the adoption of the each-, Movement analysis does not, so the formgr analysis is sup- " ported as a synchronic analysis of NE while the latter is not. 
1. The OED gives quotations up to he present for this use: B.5a." "sing. One besides. (a ) Without qualifyIng word; now only in some...or other, one...or other" (OED: other). All of the quotations after 1480 use other in one of these two ldioms; since they involve frozen forms Insume that these later quotations do not fue evidence of the normal use of other in the singular without a determiner or other qualifying word.

The type 'Q...other' is not the same sort of frozen, form, so I propose does indicate a normal use of other without $a^{*}$ dèterminer. In the 'Q...other' type, but not in the 'some/one... or other' type, the two parts of the form--the quantifier and other--can each perform a variety of different grammatical functions and often occur at opposite ends of the sentence, separated by many other lexical items that can vary freely. In the 'some/one... or other' type only a noun phrase can occur in between the two parts of the idiom.

2. The $O E D$ has also the following later quotations under thise same heading:

1685 The Indians...thinking no other but I had saved the Indian's IIfe

1690 Tis Impossible...to find any other but the setting of Mankind above the other kinds of Creatures 


\section{$\because$

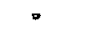 \\ 17.55
1846 \\ 1895}

This is no other than insulting a person Peter was not likely to strike with other than a right good will

2

He thought he could not doyother than

send the two prisoners for trial

I assume that 'no/any other but/than' and '(do') other

- than' represent frozen forms in NE and do not therefore give evidence of the normal use of singular other without a determiner or other qualifying word after 1561. of course, the 1561 quotation given in the text may also represent a frozen form; it is perhaps impossible to know exactly when a phrase becomes a frozen form. But for my purpose here it is sufficient to be able to say that the quoțations after' 1561 , at least, do not support. use of other alone as normal after this date.

3. If one, analyzes other in $O E$ and $M E$ as an adjeçtive only, - and in NE as both an adjective and. a noun, then 1600 Is a good date to consider as the time of re-analysis. Th1s $1 \mathrm{~s}$ when other begins to be clearly treated as a noun by regulariy showing the normal $-\underline{s}$ plural for nouns:

4. V1sser gives one example later than 1657 which he considers to be of the same type, but it is with one another": 'E'.

1867 What was to be done, asked the enraged boys one of another (Visser, p. 445) 
5. Sentences are derived from deep structures and transformations apply to deep structures or to structures interinediate between deep and surface structures, but for clarity and brevity I will speak loosely throughout this discussion about the derivation of one sen- tence from another and the application of a transformation to a sentence, and will omit mary details that are Irrelevant to the purposes of the discussion.

6. Fiengo and Lasnik (i973) have pointed out that Quantifler Movement, as formulated by. Dougherty, w111 not, in fact, yleid this. last sentence (6); Dougherty must either extend the range of positions to which Quant1fier Movement can move each or change his each-Move-

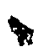
ment rule so that it can move each from a position within Aux directly into a position immediately preceding other. Both of these changes" seem possible, and efther would solve the problem.

7. Although Fiengo and Lasnik's formulation of an eachInterpretation analysis has serious defects as pointed out by, Dougherty (1974), and is untenable as presented by them, these defects are largely the results of the particular analysis-presented. Dougherty's strohgest arguments, are' against the particular scmantic interpretations assigned to each other sentences by Flengo and Lasnik, and not against a semantic analysis per sè. 
(: 8. For instance, the type of argument that suggests that the meanings of the two following sentences differ. and that they should not be related by a transformation has no foundation in a grammar in which. semantic interpretation is done of surface structure:

Each of the children hit the others.

The children hit each other.

The Interpretationiof sentences like these must ultimately be determined of course, but this involves the semántic rule of interpretation for each other sentences--a rule 'that must be present in:elther the eachMovement or each-Interpretation analysis, and seems to be independent of which analysis is selected. This sort of consideration cannot choose between the two" analyses when they are to be part of a grammar in which semantic interpretation' is done off surface structure.

9. The 'heaviness' of a noun phrase has to do with its length and complexity; $a$ prepise specification is not necessary for my purpose here since the objects in the quotations to be presented are clearly not 'heavy.'

10. I am assuming, or course, an interpretive anaiysis of all pronouns in which they are frecly generated in the base under noun (phrase) nodes and aro assigned an antecedent by an interpretive rule; see, for example, Jackendoff (1972), Dougherty (1969). 


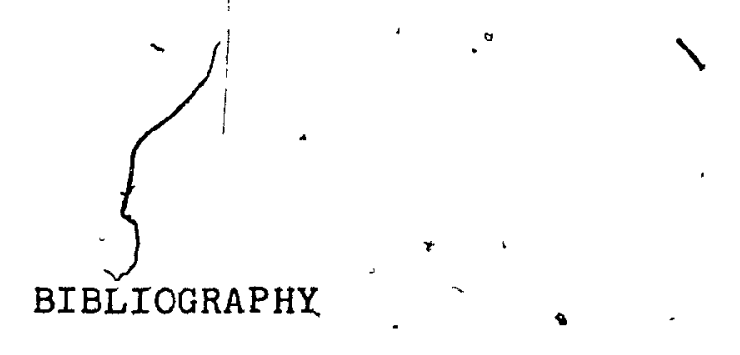

Abbott, E. A. (1897) A Shakespeartan grammar. Dover Publications, Inc.; New York.

Bright's Anglo-Saxon Reader (1935) Revised and enlarged. by James R. HuIbert. Holt, Rinekart and Winston; New York.

- Campbel1, A. (1959) old English grammar. The Clarendon.

Press: Oxford University Press; Oxford.

Chomsky, Noam (1965) Aspects of the theory of syntax.

MIT Press; Cambridge, Mass. S

(1973) "Conditions on transformations". In

Stephen Anderson \& Paul. Kiparsky (eds.), A festschrift for Morris Halle. Holt, Rinehart \& Winston; New York.

is (1975) "Conditions on rules of grammar". Mimeo.

(1976) Reflections on language. Pantheon; New York.

Curme, George 0. (1935) Parts of speech and accidence. D. C. Heath and Company; Boston.

Dougherty, Ray C. (1969) "An interpretive theory of pronominal'reference". Foundations of Language 5, 488-519.

(1970) "A grammar of coordinate conjunction, Part I". Language $46,850-98$.

(1971)" "A grammar of coordinate conjunction, Part.II". Language $47,298-339$.

(1974) "The syntax and semantics of each other constructions" " Foundations of Language 12, 1-47.

Emerson, Oliver Farrar (1948) A MIddle English reader. The Macmilian Company; New York.

Jackendoff, Ray (1972) Semantic interpretation in

generative rrammar. MIT Press; Cambridge.

Jespersen, Otto (1909-49) A Modern Engl1sh grammar on - historical principles, Vols. II-VII.. Allen \& Unwin; London. 
1
$\cdots$

KelIner, Leon (1892) Historical outlines of English syntax. Macmillan and Co.; London.

K1spert, Robert J. (1971) Old English: An introduction. HoIt, Rinehart and Winston, Inc.; New York.

Kl1ma; Edward (1964) "Relatedness among grammatical systems". Language $40,1-21$.

Lakoff, Robin (1968) Abstract syntax and Latin complementation. MIT Press; Cambridge.

Lightfoot, David (1974) "The diachronic analysis of English modals". In John Anderson \& Charles Jones (eds.), Historical linguistics I: Proceedings of the First International Conference on Historical Linguistics. North Holland; Amsterdam.

(1975) "Diachronic syntax: Extraposition and deep structure re-analyses". In Ellen Kaisse \& Jorge Hankamer (eds.), Proceedings of the 5 th meeting of the Northeastern Lingu1st1c Soc1ety. Harvard; Cambridge.

(1976) "The base component as a locus of' syntactic change". In W1lliam Christie (ed.), Proceedings of the Second. International Conference on Historical Linguisties. North Holland; Amsterdam.

(1976)* "Syntactic changè and the autonomy thesis". Paper presented at the Santa Barbara Symposium on the Mechanisms of Syntactic Change, May 1976.

Malory, Sir Thomas (1969) Le morte d'Arthur, Volume II. . Penguin Books; Baltimbre.

Middle English Dictionary (MED) (1956) University of Michigan Press; Ann Arbor.

Morris, Rev. Richard (1872) Historical outilnes of English accldence. Macmilian and Co.; London.

Mosse, Fernand (1952) "A' handbook of Middle English. Translated by James A. Walker. The Johns HopkIns Press; Baltimore.

Mustanoja, 'launo F. (1960) A Mlddle English syntax, Pant I. Societe Neophilologique; Helsinki.

Oxford Dictionary of Engl1sh Etymology. (1966) C. T. - Onions (ed.). Ciarendon Press; Oxford. 
The Oxford English Dictionary (OED) (1933) The Clarendon Press; Oxford..

Partridge, Eric (1966) Origins: A short etymological dictionary of Modern English. Rout leage \& Kegan Pau1; London.

Quirk, Randolph and C. L.'Wrenn (1955) An Old English grammar. Methuen \& Co. Ltd.; London.

Ross, J. R. (1967) "Auxiliaries as main verbs". In $W$. Todd (ed.), Studies in philosophlcal linguistics: Series one. Great Expectatfons; Evanston.

Schmidt; Alexander (1971) Shakespeare lexicon and quotation dictionary, 3rd. ed. Dover Publications; New York.

Slevers, Eduard (1903) An Old English grammar. Translated and edited by Albert S. Cook. Ginn and Company; New York.

Smith, Jesse Robert (1971) "Word order in the older: Germanic dialects" Ph.D. dissertation, University of Ililnols at Urbana-Chámpaign.

Stockwell, Robert (1976) Commentary on Lightfoot (1976). In William Christie (ed.), Prooeedings of the Second International Conference on Historical Linguistics. North Holland; Amsterdam.

Strang, Barbara M. H. (1970) A history of English. Methuen \& $\mathrm{Co}$. Ltd:; London.

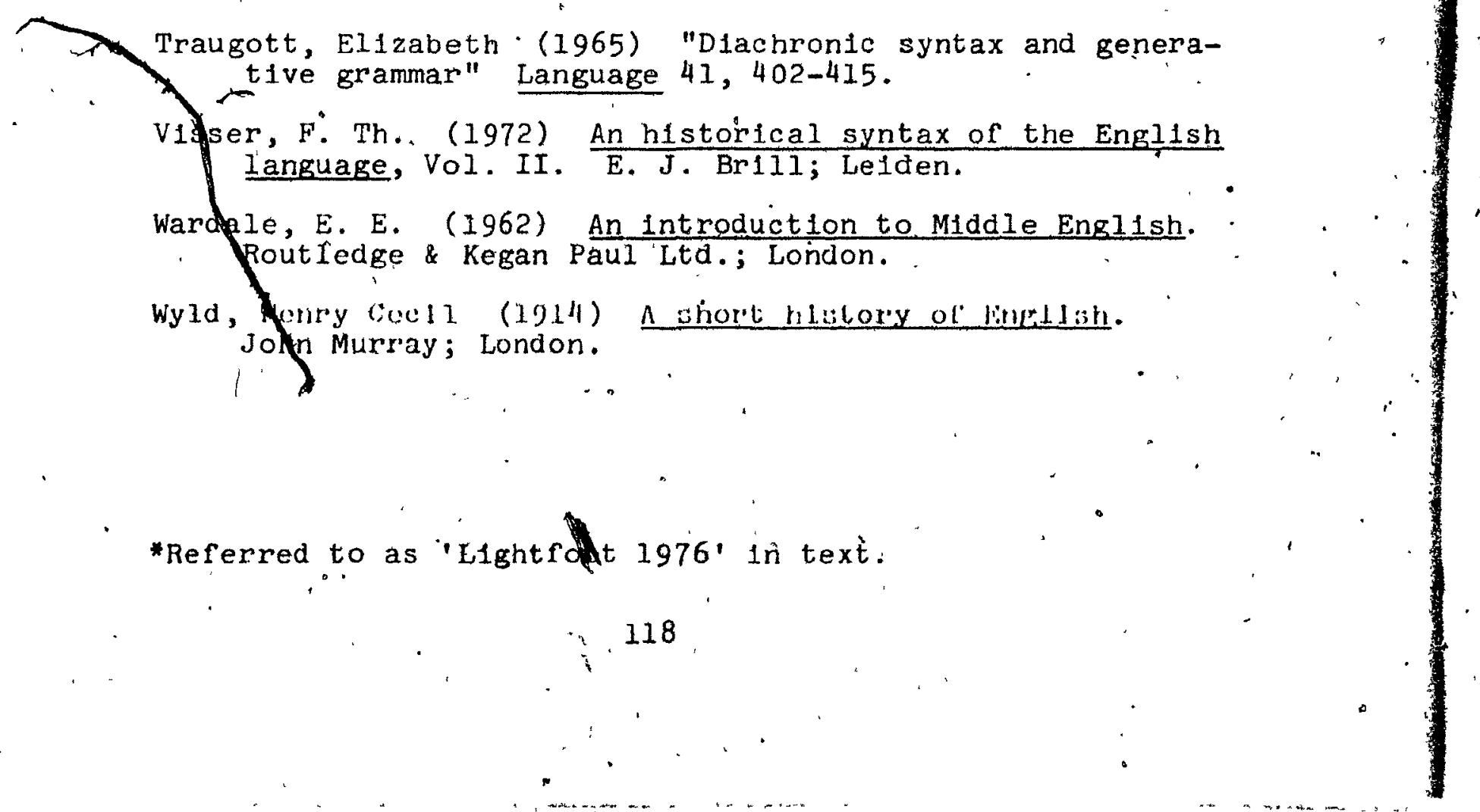

